\title{
Earthquake scenario in West Bengal with emphasis on seismic hazard microzonation of the city of Kolkata, India
}

\author{
S. K. Nath ${ }^{1}$, M. D. Adhikari ${ }^{1}$, S. K. Maiti ${ }^{1}$, N. Devaraj ${ }^{1}$, N. Srivastava ${ }^{1}$, and L. D. Mohapatra ${ }^{2}$ \\ ${ }^{1}$ Department of Geology \& Geophysics, Indian Institute of Technology Kharagpur, West Bengal, India \\ ${ }^{2}$ Aimil Ltd., New Delhi, India \\ Correspondence to: S. K. Nath (nath@gg.iitkgp.ernet.in)
}

Received: 6 November 2012 - Revised: 4 August 2014 - Accepted: 15 August 2014 - Published: 25 September 2014

\begin{abstract}
Seismic microzonation is a process of estimating site-specific effects due to an earthquake on urban centers for its disaster mitigation and management. The state of West Bengal, located in the western foreland of the AssamArakan Orogenic Belt, the Himalayan foothills and Surma Valley, has been struck by several devastating earthquakes in the past, indicating the need for a seismotectonic review of the province, especially in light of probable seismic threat to its capital city of Kolkata, which is a major industrial and commercial hub in the eastern and northeastern region of India. A synoptic probabilistic seismic hazard model of Kolkata is initially generated at engineering bedrock $\left(V_{\mathrm{s}}^{30} \sim 760 \mathrm{~m} \mathrm{~s}^{-1}\right)$ considering 33 polygonal seismogenic sources at two hypocentral depth ranges, 0-25 and 25-70 km; 158 tectonic sources; appropriate seismicity modeling; 14 ground motion prediction equations for three seismotectonic provinces, viz. the east-central Himalaya, the Bengal Basin and Northeast India selected through suitability testing; and appropriate weighting in a logic tree framework. Site classification of Kolkata performed following in-depth geophysical and geotechnical investigations places the city in D1, D2, D3 and E classes. Probabilistic seismic hazard assessment at a surface-consistent level - i.e., the local seismic hazard related to site amplification performed by propagating the bedrock ground motion with $10 \%$ probability of exceedance in 50 years through a 1-D sediment column using an equivalent linear analysis - predicts a peak ground acceleration (PGA) range from 0.176 to $0.253 \mathrm{~g}$ in the city. A deterministic liquefaction scenario in terms of spatial distribution of liquefaction potential index corresponding to surface PGA distribution places $50 \%$ of the city in the possible liquefiable zone. A multicriteria seismic hazard microzonation framework is proposed for judicious integration of multiple
\end{abstract}

themes, namely PGA at the surface, liquefaction potential index, NEHRP soil site class, sediment class, geomorphology and ground water table in a fuzzy protocol in the geographical information system by adopting an analytical hierarchal process. The resulting high-resolution surface consistent hazard, liquefaction and microzonation maps are expected to play vital roles in earthquake-related disaster mitigation and management of the city of Kolkata.

\section{Introduction}

Natural disasters inflicted by earthquakes cannot be prevented, nor is there any possibility in the near future for accurate and socially useful short-term prediction for an impending earthquake. The damage pattern due to an earthquake depends largely on the local site condition and the social infrastructure of the region, with the most important condition being the intensity of ground shaking at the time of an earthquake. A contrasting seismic response is observed even within a short distance over small changes in the geology of the site.

The challenge of urban hazard mapping is to predict the ground motion effects related to various source, path and site characteristics with an acceptable level of reliability. Seismic microzonation, recognized as priority area of an earthquake mitigation program, can be defined as the subdivision of a region that has relatively similar exposure to seismic shaking and accompanying environmental effects, such as surface faulting, liquefaction and landslides on the basis of different possible soil responses that can increase the damage. A seismic microzonation framework is shown in Fig. 1 along with the seismological and geological attributes. The 


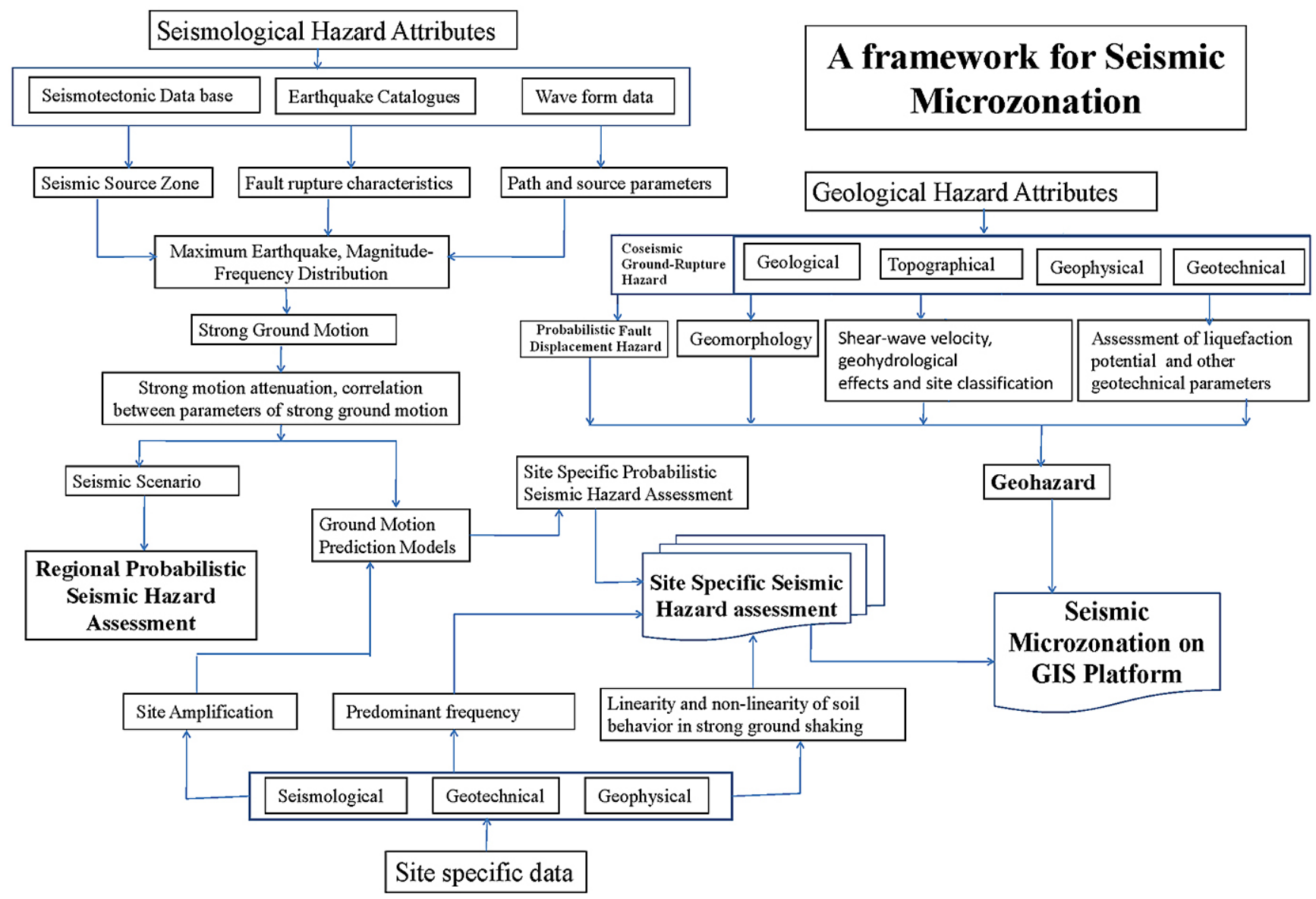

Figure 1. A microzonation framework for site-specific seismic hazard assessment.

scheme outlines a compilation of information related to seismicity, identification of potential seismic source zones, development of seismicity models, maximum earthquake prognosis supported by earthquake catalogs, and other relevant data such as tectonic database and ground rupture. The locallevel assessments involve mapping of surficial geological and geomorphological features, development of geotechnical database, and evaluation of different surficial soil attributes (e.g., density, rigidity, compressibility, damping, water content). Therefore, the seismic hazard microzonation framework encompasses the seismicity, seismic sources, and earthquake potential based on available historical and instrumental data covering hundreds of years, such as microand macro-seismicity, regional tectonics and neo-tectonics (faults/lineaments), geology, geohydrology, crustal structure, subsurface lithostratigraphy, ground-rupture hazard and soil liquefaction.

The state of West Bengal, India, located in the western foreland of the Assam-Arakan Orogenic Belt, the Himalayan foothills and Surma Valley is affected by sparse seismicity. However the occurrence of devastating earthquakes inside and around the region like the great 1897 Shillong earthquake of $M_{\mathrm{w}} 8.1$, the 1950 Assam earthquake of $M_{\mathrm{w}} 8.7$, the 1934 Bihar-Nepal earthquake of $M_{\mathrm{w}} 8.1$, the 1964 Sagar Island earthquake of $M_{\mathrm{w}} 5.4$, and the 2011 Sikkim earthquake of $M_{\mathrm{w}} 6.9$ drew attention to the seismic hazard of the province. The 1934 Bihar-Nepal earthquake of $M_{\mathrm{w}} 8.1$ inflicted considerable damage to life and property in Kolkata (GSI, 1939), adhering to the Modified Mercalli (MM) intensity of VI-VII. The near-source earthquakes reported in Kolkata include the 1906 Kolkata earthquake with MM intensity V-VI (Middlemiss, 1908), the 1885 Bengal earthquake of $M_{\mathrm{w}} 6.8$ with MM intensity V (Martin and Szeliga, 2010), the 1935 Pabna earthquake of $M_{\mathrm{w}} 6.2$ with MM intensity V (Martin and Szeliga, 2010 ) and the 1964 Sagar Island earthquake of $M_{\mathrm{w}} 5.4$ with damage intensity of MM VI-VII in the area surrounding the city of Kolkata (Nath et al., 2010). Incidentally, none of these destructive earthquakes are reported to have caused any coseismic surface ruptures in and around Kolkata. However, the maximum intensity reported in Kolkata is MM VII, generated from both the near-source earthquake of 1964 and the distant earthquake of 1934, making the province seismically vulnerable. 
The Kolkata metropolis, the focus of the present investigation, is the second largest urban agglomeration in India bounded by latitude $22^{\circ} 27^{\prime}-22^{\circ} 40^{\prime} \mathrm{N}$ and longitude $88^{\circ} 18^{\prime}-$ $88^{\circ} 28^{\prime}$ E. It has developed primarily along the eastern bank of the River Hooghly during the last $300+$ years. The city is located about $150 \mathrm{~km}$ north of the Bay of Bengal, right over the Ganges Delta. The flat topography of Kolkata has an average elevation of $6.4 \mathrm{~m}$ a.m.s.l. (above mean sea level), the highest location is about $9.5 \mathrm{~m}$ at Netaji Subhas Chandra Road (Clive Street), and the lowermost place is Mechhua at an elevation of $5.5 \mathrm{~m}$. The population of Kolkata, which was 1.5 million in the year 1901, had a phenomenal increase to 14 million as per the census report of 2011, thus making it one of the most densely populated regions in the world. It also supports vital industrial and transportation infrastructure. The city is situated on a sedimentary deposit with a thickness of the order of $7.5 \mathrm{~km}$ that is above the crystalline basement. The city is highly developed, with many old buildings, bridges, subways, tall structures, huge shopping malls, and lifeline facilities (hospitals, emergency services, etc.) that require earthquake disaster mitigation and safety regulations.

The prevailing seismic zoning map of India (BIS, 2002) prepared based on the peak ground acceleration (PGA) induced by the maximum considered earthquake (MCE) further constrained by the geologic and seismotectonic considerations, thus scaling it down to the design basis earthquake (DBE) for urban codal provisions, places the entire city of Kolkata at the boundary between zone III and IV, with an equivalent PGA range of $0.16-0.24 \mathrm{~g}$. As per this zonation scheme, zone $\mathrm{V}$ is the highest expected level of seismic hazard, with a PGA level of $0.36 g$ and MM intensity of VIII (and above), while seismic zone IV corresponds to $0.24 \mathrm{~g}$ PGA, adhering to MM intensity VII. Further, seismic zone III corresponds to $0.16 g$ PGA and MM intensity VI, whereas zone II is associated with the lowest level of hazard, with a PGA level of $0.10 \mathrm{~g}$ and MM intensity of V (or less).

\section{Geology and tectonic setting of West Bengal and its adjoining region}

The Bengal Basin, in the northeastern part of the Indian subcontinent between the Indian Shield and Indo-Burman Ranges, comprises three geotectonic provinces: (1) the stable shelf, (2) the central deep basin (extending from the Sylhet Trough in the northeast towards the Hatia Trough in the south), and (3) the Chittagong-Tripura Fold Belt, as shown in Fig. 2a. The dynamic nature of the Bengal Basin can be attributed to the interaction of three plates, namely the Indian, Tibetan (Eurasian) and Burma (West Burma Block) plates. The intensity and pattern of plate-to-plate interaction varied with time, affecting the basin architecture and sedimentation style throughout the basin (Alam et al., 2003). The basin is structurally divided into five tectonic elements from northwest to southeast: (1) the North Bengal foreland,
(2) basin margin fault zone (western scarp zone), (3) stable shelf, (4) hinge zone or shelf/slope break, and (5) deep basin, as shown in Fig. 2 a and the W-E geological cross section in Fig. 2b. The most prominent tectonic feature in the Bengal Basin is the NE-SW-trending Eocene Hinge Zone (EHZ), also known as the Calcutta-Mymensing Hinge Zone, which is $25 \mathrm{~km}$ wide and extends to a depth of about $4.5 \mathrm{~km}$ below Kolkata, reportedly triggered an earthquake of magnitude $M_{\mathrm{W}} 6.2$ in 1935 , with the epicenter at lat $24^{\circ} 255^{\prime} \mathrm{N}$, long $89^{\circ} 495^{\prime} \mathrm{E}$, that mostly affected Bangladesh, but a prolonged tremor was felt at Kolkata. The EHZ is covered by an upper Paleozoic to Holocene sedimentary fill to a maximum thickness of about $7.5 \mathrm{~km}$. The other major tectonic features of this region are the Garhmoyna-Khandaghosh Fault, Jangipur-Gaibandha Fault, Pingla Fault, Debagram-Bogra Fault, Rajmahal Fault, Malda-Kishanganj Fault, SainthiaBahmani Fault, Purulia Shear Zone, main boundary thrust, main central thrust, Tista Lineament, and Purulia Lineament, as depicted in Fig. 2a. In the region of Northeast India, major faults, such as the Dauki Fault, Oldam Fault and Dhubri Fault, marking the boundary of the strikingly elevated Shillong Plateau also pose a seismic threat to West Bengal and in particular Kolkata.

\section{Probabilistic seismic hazard assessment (PSHA) framework for Kolkata at engineering bedrock}

\subsection{Seismogenic source definition in the region}

A successful seismogenic source definition requires a declustered homogeneous earthquake catalog of the study region. We therefore prepared an earthquake catalog of the Bengal Basin and the adjoining region spanning the 1900-2012 period by considering three major earthquake data sources, namely the International Seismological Centre (ISC, http: //www.isc.ac.uk), the US Geological Survey/National Earthquake Information Center (USGS/ NEIC, http://neic.usgs. gov.us), and the Global Centroid Moment Tensor Project (GCMT, http://www.globalcmt.org), wherein the hypocentral depth entries have been computed using the algorithm given by Engdahl et al. (1998). Other data sources used include the India Meteorological Department (IMD, http: //www.imd.ernet.in), and Jaiswal and Sinha (2004). For uniform magnitude scaling and establishing data homogeneity for meaningful statistical analysis, $M_{\mathrm{W}}$ is preferred owing to its applicability for all ranges of earthquakes, i.e., for large or small, far or near, and shallow- or deep-focus earthquakes. Thereafter, the entire catalog has been declustered to remove foreshocks and aftershocks to derive a main-shock catalog accessible at http://www.earthqhaz.net/sacat/. The fault database is compiled with a geographical information system (ArcGIS 9.1). The sources include seismotectonic map of India published by the Geological Survey of India (Dasgupta et al., 2000) and the one extracted from Landsat TM/MSS and 



Figure 2. (a) Seismotectonic system of West Bengal and its adjoining region (lat 19.6 to $28.3^{\circ} \mathrm{N}$, long 85.4 to $92.9^{\circ} \mathrm{E}$ ) (modified considering Dasgupta et al., 2000; USGS-BGAT, 2001; and GSB, 1990) and (b) a W-E geological cross section depicting the lithostratigraphy and structural setting of the Bengal Basin (modified from Alam et al., 2003).

SRTM data. To characterize the seismogenic sources responsible for significantly contributing to the seismic hazard of Kolkata, the earthquakes from the catalog supplemented by records of historical earthquakes (occurring prior to 1900 and as early as AD 819) and instrumental data covering a period from 1900-2012 are projected with the fault pattern in the region. Thus, in the present study, we classified seismogenic sources based on two categories, viz. (a) layered polygonal sources and (b) active tectonic sources.

\subsubsection{Layered polygonal seismogenic source zones}

A popular approach in the seismogenic localization process is the areal source zonation, wherein the objective is to capture uniform seismicity. The seismicity pattern and seismogenic source dynamics are known to have significant variations with depth (e.g., Prozorov and Dziewonski, 1982; Christova, 1992; Tsapanos, 2000; Allen et al., 2004; Nath and Thingbaijam, 2012). This has been considered by scientists in other parts of the globe (e.g., Stirling et al., 2002; 

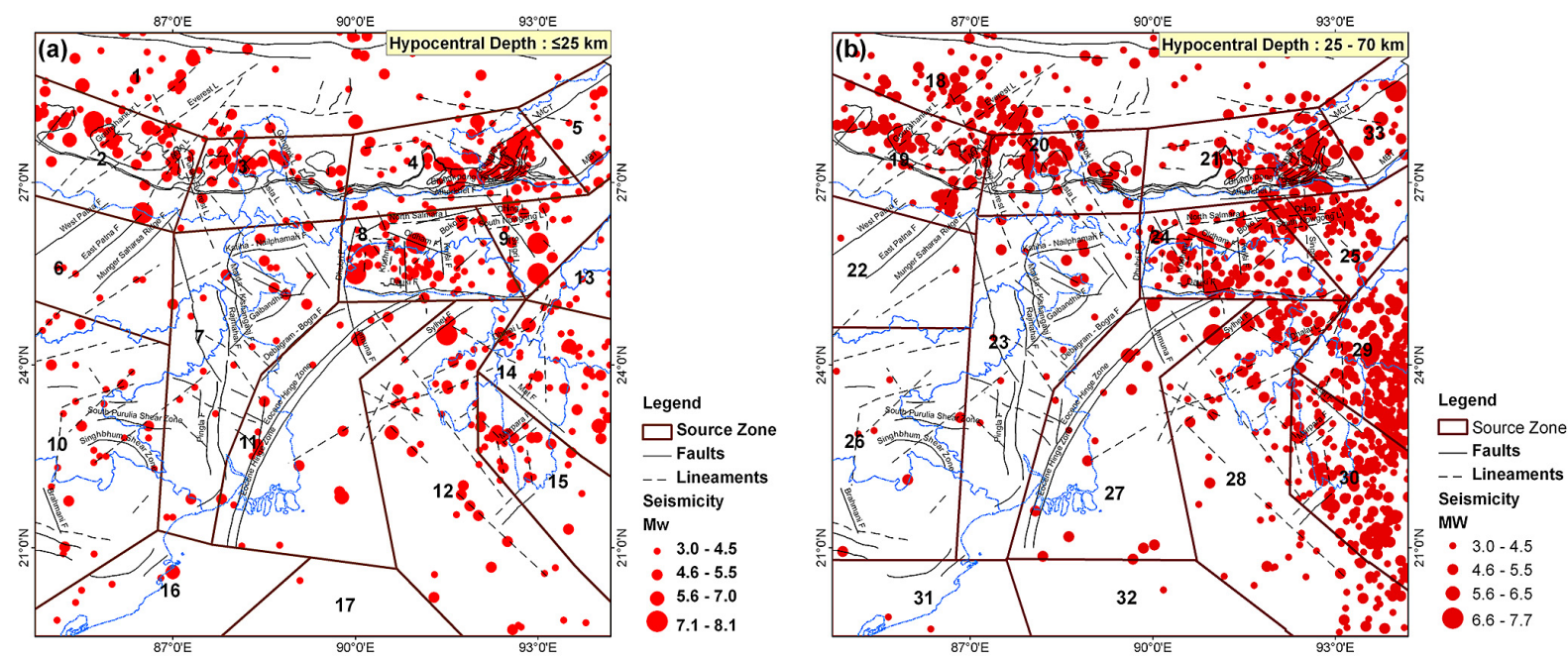

Figure 3. A layered polygonal seismogenic source framework for West Bengal and its adjoining region modified after Nath and Thingbaijam (2012) for PSHA (a) hypocentral depth of 0-25 km and (b) hypocentral depth of 25-70 km.

Suckale and Grünthal, 2009). Hence, considering a single set of seismicity parameters over the entire depth range may generate an incorrect hazard estimation. Based on the hypocentral depth of seismicity in this region, two hypocentral depth ranges (in kilometers) $-0-25$ and 25-70 - are considered. Thereafter, the zonation is carried out based on seismicity patterns, fault networks and similarity in the style of focal mechanisms (e.g., Cáceres et al., 2005) demarcating 33 source zones as depicted in Fig. 3. The layered model is expected to facilitate in resolving the source characteristics more precisely than the conventional single-layer schemes considered hitherto by other authors.

In real situations, it is difficult at times to establish a definite tectonic class for a given zone. While the source zonation becomes a case of tectonic dismantling, reduced seismogenic zone dimensions with sparse earthquake occurrences would obscure seismicity parameterization. In that respect, seismicity smoothing or a zone-free approach is considered pragmatic to account for the absence of fault associability while adhering to the spatial distribution of earthquake occurrences. This complies with the fact that the locations of future large earthquakes tend to follow those of the past seismicity (Kafka, 2007; Parsons, 2008). The approach has been in vogue since the works of Vere-Jones (1992), Kagan and Jackson (1994) and Frankel (1995). Recent studies have employed seismicity smoothing for small to moderate earthquakes and fault-specific zonation for larger earthquakes (e.g., Petersen et al., 2008; Kalkan et al., 2009). Alternatively, a unified approach can be formulated such that seismicity models based on area zonation are employed for the estimation of $b$ values and $m_{\max }$, while seismicity smoothing is used to establish the distribution of the seismic activity rate. This delineates the grid cells according to regions of homogenous seismotectonic characteristics. Eventually, the methodology adopted in the present study can be outlined as (1) delineation of areal source zones, (2) derivation of a seismicity model for each zone, and (3) application of a seismicity-smoothing algorithm to obtain activity rates for specific threshold magnitudes.

\subsubsection{Active tectonic source zones}

Additional seismic sources considered are the active tectonic features such as faults and lineaments (Azzaro et al., 1998; Slemmons and McKinney, 1977). As discussed earlier, the Bengal Basin encompasses many active faults and lineaments which can be considered potential sources contributing to the seismic hazard of the region. In the present study, active tectonic features are extracted from the seismotectonic atlas of India (Dasgupta et al., 2000), and additional features are extracted via image processing of Landsat TM data (http://glovis.usgs.gov/) through edge enhancement filtering and principal component analysis. The focal mechanism data employed in the present study are derived from the Global Centroid Moment Tensor Project (GCMT, www.globalcmt. org) database, covering the period from 1976 to 2012, and other studies, viz. Dasgupta et al. (2000), Chandra (1977), Singh and Gupta (1980) and Bilham and England (2001). Therefore, we have identified about 158 tectonic features (i.e., faults and lineaments) in the $0-25$ and $25-70 \mathrm{~km}$ depth ranges that have the potential to generate earthquakes of $M_{\mathrm{w}} 3.5$ and above. Figure 4 depicts major active tectonic sources of West Bengal and its adjoining region.

The deterministic assessment of characteristic earthquakes, viz. maximum earthquakes from a fault, is generally achieved by means of a relationship between earthquake magnitude and coseismic subsurface fault rupture length. The primary method used to estimate subsurface rupture 
Table 1. A list of major active tectonics which are considered to be seismic sources, along with total fault length (TFL), observed maximum earthquake $\left(M_{\text {max,obs }}\right)$, subsurface rupture length (RLD), and estimated maximum earthquake $\left(M_{\max }\right)$ in Kolkata and adjoining regions.

\begin{tabular}{lrllrc}
\hline Fault name & TFL & $M_{\text {max,obs }}$ & Fault type & RLD & $M_{\text {max }}$ \\
\hline Pyudung Thrust Fault & 172 & 5.1 & Reverse & 46 & $7.0( \pm 0.26)$ \\
Main boundary thrust & 725 & 6.6 & Reverse & 74 & $7.3( \pm 0.26)$ \\
Dhubri Fault & 248 & 7.1 & Reverse & 175 & $7.8( \pm 0.26)$ \\
Atherkhet Fault & 143 & 5.2 & Strike slip & 20 & $6.3( \pm 0.24)$ \\
Dhansiri-Kopili Fault & 142 & 4.8 & Strike slip & 25 & $6.4( \pm 0.24)$ \\
Bomodila Fault & 83 & 4.9 & Reverse & 34 & $6.8( \pm 0.26)$ \\
Kalaktang Fault & 105 & 5.2 & Reverse & 18 & $6.4( \pm 0.26)$ \\
Sylhet Fault & 234 & 7.6 & Strike slip & 198 & $7.8( \pm 0.24)$ \\
Pyudung Fault & 142 & 5.6 & Reverse & 24 & $6.5( \pm 0.26)$ \\
Main central thrust & 468 & 6.5 & Reverse & 123 & $7.6( \pm 0.26)$ \\
Main frontal thrust & 103 & 5.3 & Reverse & 23 & $6.5( \pm 0.26)$ \\
Eocene Hinge & 608 & 6.2 & Strike slip & 47 & $6.8( \pm 0.24)$ \\
Dauki Fault & 342 & 7.1 & Strike slip & 110 & $7.4( \pm 0.24)$ \\
Everest Lineament & 324 & 5.2 & Strike slip & 35 & $6.6( \pm 0.24)$ \\
Gourishankar Lineament & 293 & 5.6 & Strike slip & 63 & $7.0( \pm 0.24)$ \\
Tista Lineament & 257 & 5.5 & Strike slip & 70 & $7.1( \pm 0.24)$ \\
Gangtok Lineament & 44 & 5 & Strike slip & 19 & $6.2( \pm 0.24)$ \\
Arun Lineament & 265 & 6.8 & Oblique reverse & 65 & $7.2( \pm 0.26)$ \\
Himalayan Frontal Thrust & 387 & 8.1 & Reverse & 335 & $8.3( \pm 0.26)$ \\
Krishnai Lineament & 80 & 4.9 & Strike slip & 17 & $6.1( \pm 0.24)$ \\
Jangipur-Gaibanda Fault & 48 & 4.1 & Strike slip & 4.9 & $5.3( \pm 0.24)$ \\
Jamuna Fault & 124 & 6.8 & Strike slip & 80 & $7.2( \pm 0.24)$ \\
\hline & & & & & \\
\hline & & & & & \\
& & & & &
\end{tabular}

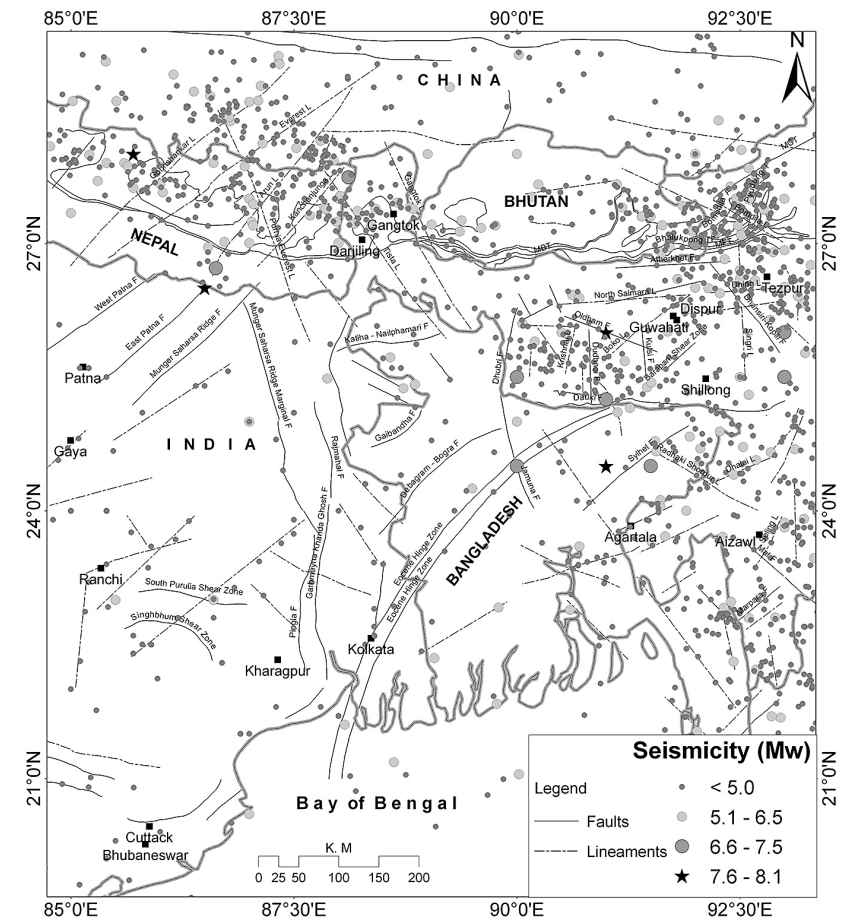

Figure 4. Major active tectonic sources of West Bengal and its adjoining region. length and rupture area is the spatial pattern of early aftershocks (Wells and Coppersmith, 1994). Aftershocks that occur within a few hours to a few days of the mainshock generally define the maximum extent of coseismic fault rupture (Kanamori and Anderson, 1975; Dietz and Ellsworth, 1990; Wong et al., 2000). Basically, an aftershock zone roughly corresponds to the fault ruptured during the mainshock; precise studies indicate that aftershocks are concentrated near the margin of the fault area where the large displacement occurred (e.g., Das and Henry, 2003; Utsu, 2002). The general assumption, based on worldwide data, is that one-third to one-half of the total length of fault would rupture when it generates the maximum earthquake (Mark, 1977; Kayabalia and Akin, 2003; Shukla and Choudhury, 2012; Seyrek and Tosun, 2011). In the present study, the fault rupture segmentation was identified using the maximum length of the well-defined mainshock and aftershock zone along the faults (Besana and Ando, 2005; Utsu, 2002; Wells and Coppersmith, 1994); thereafter a GIS-based on-screen digitization method was used for the estimation of subsurface rupture length of each active tectonic feature. The maximum credible earthquake has been estimated using the relationship given by Wells and Coppersmith (1994) based on subsurface fault rupture dimension and magnitude. Table 1 lists some major active tectonic sources, their total length (TFL), the associated observed maximum earthquakes $\left(M_{\max , o b s}\right)$, the subsurface rupture length (RLD) and the maximum predicted earthquake $\left(M_{\max }\right)$. 


\subsection{Seismicity analysis}

The evaluation of seismicity parameters is one of the most important steps for hazard estimation. Earthquake occurrences across the globe follow the Gutenberg-Richter (GR) relationship,

$\log _{10} \lambda(m)=a-b m$,

where $\lambda(m)$ is the cumulative number of events with magnitude $\geq m$ (Gutenberg and Richter, 1944). The slope parameter, commonly referred to as the $b$ value, is often employed as an indicator of the stress regime in the tectonic reinforcements, and to characterize seismogenic zones (Schorlemmer et al., 2005). The maximum likelihood method to estimate the $b$ value given by Aki (1965) and Utsu (1965) is as follows:

$b=\frac{\log _{10}(e)}{\left[m_{\text {mean }}-\left(m_{t}-\frac{\Delta m}{2}\right)\right]}$,

where $m_{\text {mean }}$ is the average magnitude, $m_{t}$ is the minimum magnitude of completeness, and $\Delta m$ is the magnitude bin size ( 0.1 in the present study). The standard deviation of the $b$ value $(\delta b)$ has been computed by means of the bootstrapping method, as suggested by Schorlemmer et al. (2003), which involves repeated computations, each time employing a redundant data sample, allowing events drawn from the catalog to be selected more than once. A minimum magnitude constraint is generally applied on the GR relation given by Eq. (1) on the basis of the magnitude of completeness entailed by the linearity of the GR relation on the lower magnitude range. An upper magnitude has been suggested in accordance with physical dissipation of energy and constraints due to the tectonic framework (Kijko, 2004). This is achieved by establishing the maximum earthquake $m_{\max }$ physically capable of occurring within a defined seismic regime in an underlying tectonic setup. The magnitude distribution is therefore truncated at $m_{\max }$ such that $m_{\max } \gg m_{\min }$. A modified version of Eq. (1) formulated by Page (1968) and Cornell and Vanmarcke (1969) is a truncated exponential distribution termed as truncated Gutenberg-Richter (TGR) frequencymagnitude relationship as follows:

$\lambda(m)=\lambda\left(m_{\min }\right) \frac{10^{-b\left(m-m_{\min }\right)}-10^{-b\left(m_{\max }-m_{\min }\right)}}{1-10^{-b\left(m_{\max }-m_{\min }\right)}}$,

where $m_{\min }$ is minimum magnitude and $m_{\max }$ is an upperbound magnitude. The maximum earthquake $\left(M_{\max }\right)$ is the largest seismic event characteristic of the terrain under the tectonostratigraphic consideration. The $b$ value and $a$ value are estimated by applying the maximum likelihood method (Aki, 1965; Utsu, 1965) on the instrumental catalog. The incomplete data (including the historical data) are rendered return periods according to the models, namely the GR and truncated GR (TGR) models. The linear GR relation can statistically accommodate large events if the seismic source
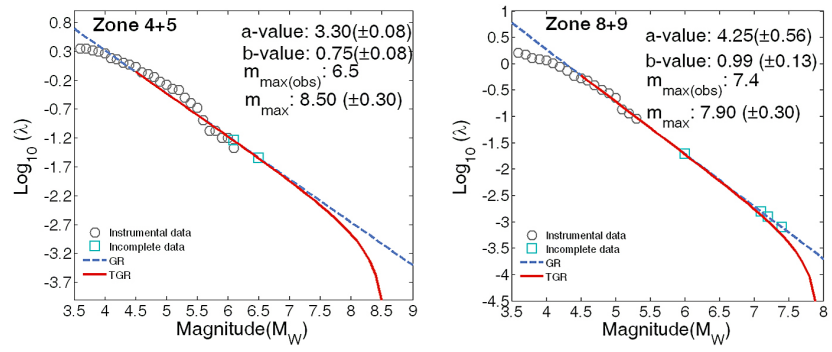

Figure 5. Representative frequency-magnitude distribution plots at some typical polygonal seismogenic sources: zones $4+5$ and zones $8+9$. The red line represents truncated Gutenberg-Richter (TGR) relation; the blue line represent the Gutenberg-Richter (GR) relation; and the circles and squares represent the instrumental events (complete data coverage) and incomplete data (including the historical data as extreme data coverage), respectively.

zone is of appropriate size and the temporal coverage of the catalog is also long enough; the TGR model is assumed to be more appropriate considering the energy dissipations at larger magnitudes. For polygonal sources, a maximum likelihood method for maximum earthquake estimation referred to as Kijko-Sellevoll-Bayesian (Kijko, 2004) has been used. In several cases, zones with similar tectonics are merged to achieve a sufficient number of events, i.e., $\geq 50$, as well as an acceptable uncertainty with the estimated seismicity parameters. This produced 21 zones out of a total of 33. Sample frequency-magnitude distribution plots for a few polygonal seismogenic sources are given in Fig. 5. The seismicity parameters estimated for all the polygonal seismogenic sources are listed in Table 2.

\subsection{Smoothed seismicity model}

The contribution of background seismicity in the hazard perspective is estimated using smoothened gridded seismicity models. This allows modeling for of discrete earthquake distributions into spatially continuous probability distributions. The technique given by Frankel (1995) is employed in the present study. The entire region is gridded at a regular interval of $0.1^{\circ}$, with each grid point encompassing a cell of $0.1^{\circ} \times 0.1^{\circ}$, which represents about $11 \mathrm{~km}^{2}$. The smoothened function is given by

$N_{i}\left(m_{\mathrm{r}}\right)=\frac{\sum_{j} n_{j}\left(m_{\mathrm{r}}\right) e^{-\left(d_{i j} / c\right)^{2}}}{\sum_{j} e^{-\left(d_{i j} / c\right)^{2}}}$,

where $n_{j}\left(m_{\mathrm{r}}\right)$ is the number of events with magnitude $\geq m_{\mathrm{r}}$, $d_{i j}$ is the distance between $i$ th and $j$ th cells, and $c$ denotes the correlation distance. The annual activity rate $\lambda_{m_{\mathrm{r}}}$ is computed each time as $N_{i}\left(m_{\mathrm{r}}\right) / T$, where $T$ is the (sub)catalog period. The present analyses make use of subcatalogs for the periods 1990-2012, 1964-2012 and 1903-2012, with threshold 
Table 2. Estimated seismicity parameters for all the polygonal seismogenic sources considered for PSHA in Kolkata.

\begin{tabular}{lcccc}
\hline Zone & $b$ value & $a$ value & $\begin{array}{c}M_{\text {max }} \\
\text { predicted })\end{array}$ & $\begin{array}{c}\text { Observed } \\
\left(M_{\max }\right)\end{array}$ \\
\hline Zone 1 & $0.73( \pm 0.14)$ & $3.02( \pm 0.59)$ & $7.70( \pm 0.40)$ & 6.9 \\
Zone 2 & $0.82( \pm 0.12)$ & $3.54( \pm 0.45)$ & $8.80( \pm 0.20)$ & 8.1 \\
Zone 3 & $0.54( \pm 0.07)$ & $1.96( \pm 0.36)$ & $8.30( \pm 0.30)$ & 6.2 \\
Zone 4+5 & $0.75( \pm 0.08)$ & $3.30( \pm 0.08)$ & $8.50( \pm 0.30)$ & 6.5 \\
Zone 6+7+11 & $0.84( \pm 0.16)$ & $3.22( \pm 0.59)$ & $7.20( \pm 0.30)$ & 6.8 \\
Zone 8+9 & $0.99( \pm 0.13)$ & $4.25( \pm 0.56)$ & $7.90( \pm 0.30)$ & 7.4 \\
Zone 10 & $0.65( \pm 0.14)$ & $2.00( \pm 0.32)$ & $7.00( \pm 0.40)$ & 5.5 \\
Zone 12 & $0.77( \pm 0.10)$ & $2.96( \pm 0.63)$ & $8.80( \pm 0.40)$ & 7.4 \\
Zone 13+14 & $0.63( \pm 0.15)$ & $2.32( \pm 0.63)$ & $8.20( \pm 0.40)$ & 6.4 \\
Zone 15 & $0.99( \pm 0.18)$ & $4.16( \pm 0.41)$ & $8.20( \pm 0.40)$ & 5.6 \\
Zone 16+17+26+31 +32 & $0.57( \pm 0.15)$ & $1.64( \pm 0.45)$ & $6.80( \pm 0.30)$ & 5.8 \\
Zone 18 & $1.31( \pm 0.15)$ & $5.93( \pm 0.50)$ & $7.10( \pm 0.30)$ & 6.0 \\
Zone 19 & $0.88( \pm 0.14)$ & $3.91( \pm 0.32)$ & $8.30( \pm 0.20)$ & 6.8 \\
Zone 20 & $0.93( \pm 0.13)$ & $3.95( \pm 0.32)$ & $8.30( \pm 0.20)$ & 6.5 \\
Zone 21+33 & $0.98( \pm 0.09)$ & $4.44( \pm 0.32)$ & $8.30( \pm 0.20)$ & 7.7 \\
Zone 22+23+27 & $0.92( \pm 0.13)$ & $3.77( \pm 0.50)$ & $6.50( \pm 0.30)$ & 6.2 \\
Zone 24 & $0.91( \pm 0.07)$ & $3.93( \pm 0.45)$ & $8.30( \pm 0.20)$ & 8.1 \\
Zone 25 & $1.21( \pm 0.15)$ & $5.35( \pm 0.54)$ & $7.20( \pm 0.40)$ & 5.8 \\
Zone 28 & $0.99( \pm 0.13)$ & $4.41( \pm 0.63)$ & $8.80( \pm 0.40)$ & 7.6 \\
Zone 29 & $1.06( \pm 0.10)$ & $4.83( \pm 0.41)$ & $7.90( \pm 0.40)$ & 6.2 \\
Zone 30 & $0.98( \pm 0.10)$ & $4.65( \pm 0.41)$ & $7.90( \pm 0.40)$ & 6.5 \\
\hline & & & & \\
\hline
\end{tabular}
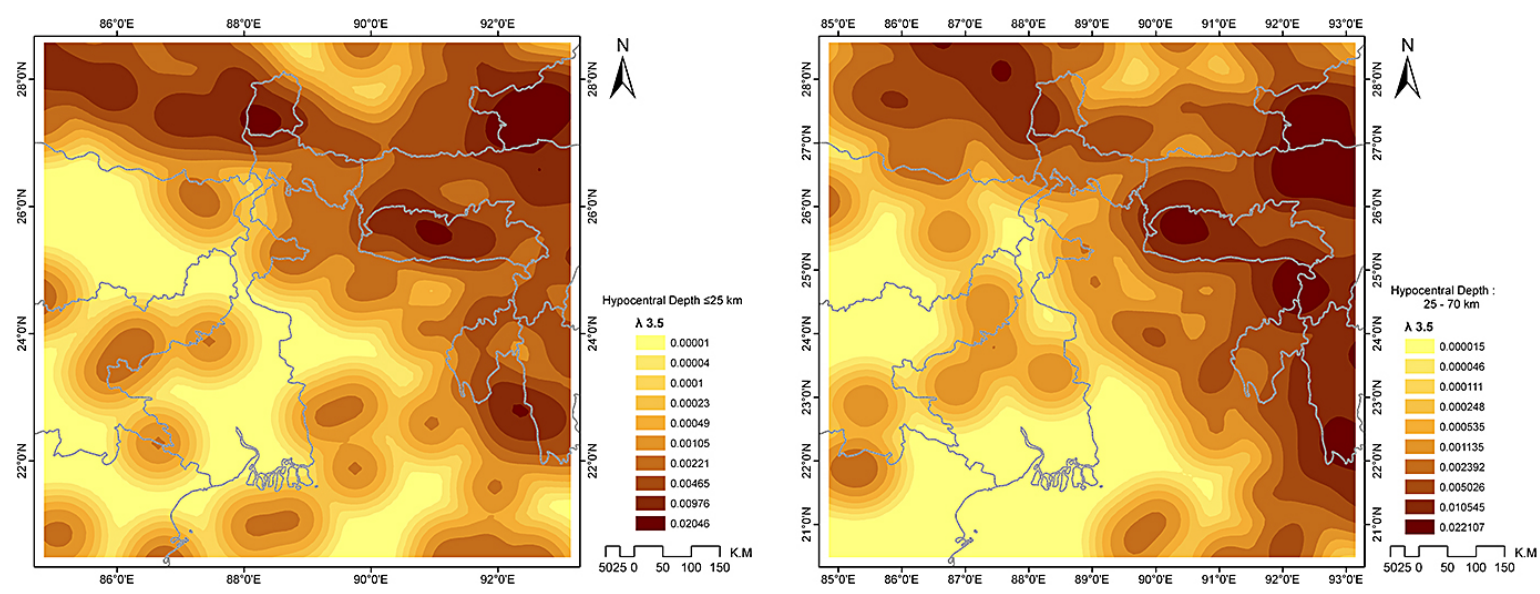

Figure 6. Smoothed seismicity in West Bengal and its adjoining region for a threshold magnitude of $M_{\mathrm{W}} 3.5$ at two hypocentral depth regions (0-25 and $25-70 \mathrm{~km}$ ) indicating the seismic activity distribution (frequency of occurrence of a magnitude $M_{\mathrm{W}} \geq 3.5$ per year considering an earthquake catalog of the region for the period 1900-2012).

magnitudes of $M_{\mathrm{w}} 3.5,4.5$ and 5.5, respectively, as summarized in Table 3. Correlation distances of 55, 65 and $85 \mathrm{~km}$ are decided for the respective cases by calibrating the outputs from several runs of the algorithm with the observed seismicity. The smoothened seismicity analysis is performed for the threshold magnitudes of $M_{\mathrm{w}} 3.5,4.5$ and 5.5, with the results of $M_{\mathrm{w}} 3.5$ at the hypocentral depth ranges $0-25$ and $25-70 \mathrm{~km}$ being displayed in Fig. 6. Likewise, the seismic activity rates for each active tectonic source within a $25 \mathrm{~km}$ buffer around each are also computed using the threshold magnitudes of $M_{\mathrm{w}} 3.5,4.5$ and 5.5 at both the hypocentral depth ranges. 

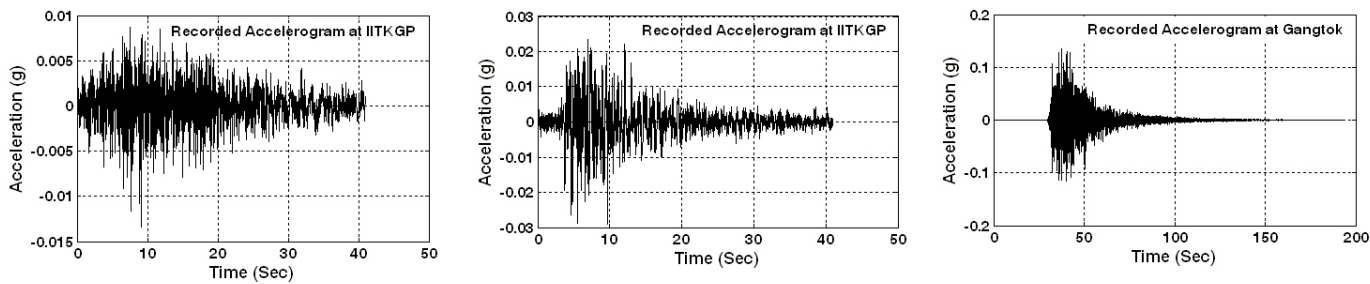

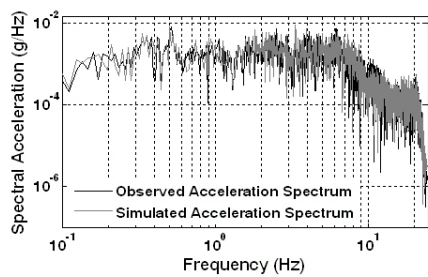

(a)
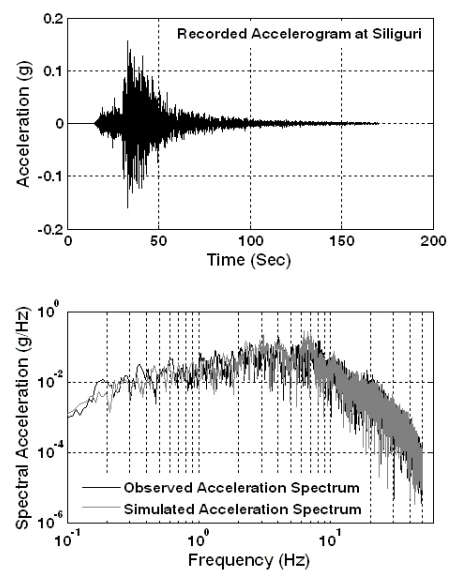

(d)

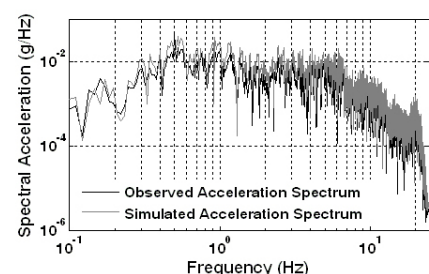

(b)
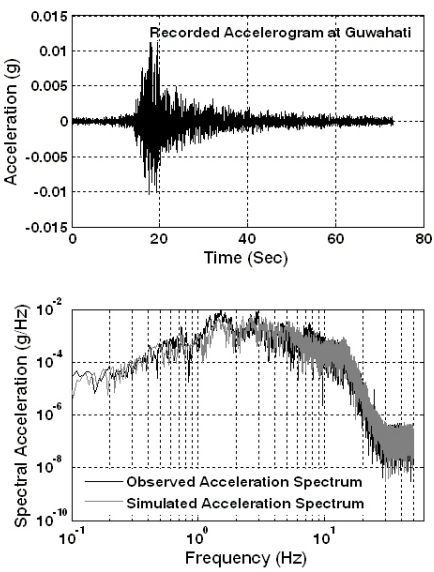

(e)

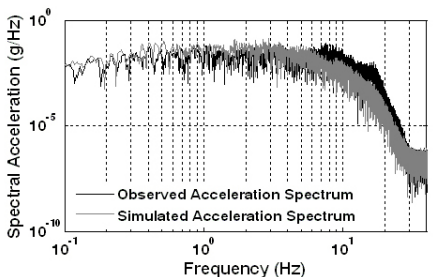

(c)
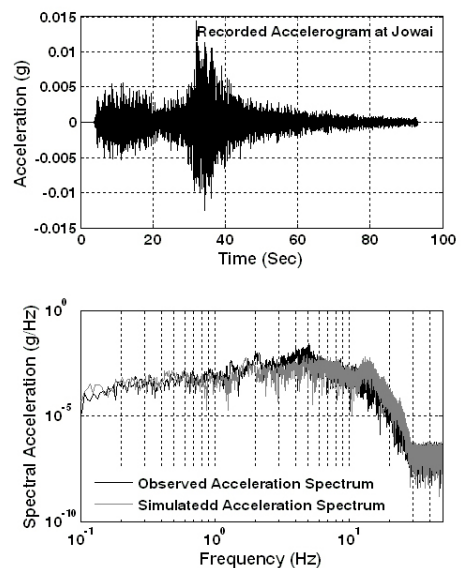

(f)

Figure 7. Recorded accelerograms and comparison of the observed and simulated acceleration spectra of (a) the 13 December 2005 earthquake of $M_{\mathrm{W}} 4.0$, (b) the 6 February 2008 earthquake of $M_{\mathrm{W}} 4.9$ recorded at the IIT Kharagpur (IITKGP) Broadband Observatory for the Bengal Basin seismogenic source, (c) the 18 September 2011 Sikkim earthquake of $M_{\mathrm{W}} 6.9$ recorded at Gangtok, (d) the Siliguri strong motion station of DSSMN for the east-central Himalaya seismogenic source, (e) the 18 August 2009 Myanmar-India border earthquake of $M_{\mathrm{W}} 5.6$ recorded at Guwahati, and (f) the 4 February 2011 Myanmar-India border earthquake of $M_{\mathrm{W}} 6.4$ recorded at the Jowai strong motion station of PESMOS (http://pesmos.in) for the Northeast India seismogenic source.

Table 3. The subcatalogs for the three different threshold magnitudes considered for the construction of seismicity grids.

\begin{tabular}{lccc}
\hline \multirow{2}{*}{$\begin{array}{l}\text { Depth range } \\
(\mathrm{km})\end{array}$} & \multicolumn{3}{c}{ Subcatalog (threshold magnitude) } \\
\cline { 2 - 4 } & $M_{\mathrm{W}} 3.5$ & $M_{\mathrm{W}} 4.5$ & $M_{\mathrm{W}} 5.5$ \\
\hline $0-25$ & $1990-2012$ & $1964-2012$ & $1903-2012$ \\
$25-70$ & $1990-2012$ & $1964-2012$ & $1902-2012$ \\
\hline
\end{tabular}

\subsection{Ground motion prediction equations}

The ground motion parameters at a site of interest are evaluated by using a ground motion prediction equation that relates a specific strong motion parameter of ground shaking to one or more seismic attributes (Campbell and Bozorgnia, 2003). In the study region, a strong motion network recorded several moderate intensity earthquakes (Nath, 2004; Pal et al., 2008; Raj et al., 2008) from the near and distant fields from within the Bengal Basin, east-central Himalaya and Northeast India. Due to paucity of good magnitude coverage of strong ground motion data, analytical or numerical approaches for a realistic prognosis of possible seismic effects in terms of tectonic regime, earthquake size, local geology, and near-fault conditions necessitate systematic ground motion synthesis. In order to strengthen the ground motion database, the seismic events of small to moderate magnitude recorded by the Darjeeling-Sikkim strong motion network (DSSMN) of IIT Kharagpur, PESMOS (http://pesmos.in) of IIT Roorke, the IIT Guwahati strong motion network in the 
Table 4. Parameters used for strong ground motion simulation*.

\begin{tabular}{|c|c|c|c|}
\hline Parameter & $\begin{array}{l}\text { East-central Himalaya } \\
\text { source zone }\end{array}$ & $\begin{array}{l}\text { Bengal Basin } \\
\text { source zone }\end{array}$ & $\begin{array}{l}\text { Northeast India } \\
\text { source zone }\end{array}$ \\
\hline Strike & $285^{\circ}$ & $232^{\circ}$ & $112^{\circ}$ \\
\hline Dip & $6^{\circ}$ & $32^{\circ}$ & $50^{\circ}$ \\
\hline Focal depth (km) & 20 & 35.9 & 35 \\
\hline Source (location) & $27.55^{\circ} \mathrm{N}, 87.09^{\circ} \mathrm{E}$ & $21.6^{\circ} \mathrm{N}, 88.07^{\circ} \mathrm{E}$ & $26.0^{\circ} \mathrm{N}, 91.0^{\circ} \mathrm{E}$ \\
\hline Stress (bar) & 275 & 30 & 159 \\
\hline Crustal density $\left(\mathrm{g} \mathrm{cm}^{-3}\right)$ & 2.7 & 2.7 & 2.7 \\
\hline Shear wave velocity $(\beta)\left(\mathrm{km} \mathrm{s}^{-1}\right)$ & 3.8 & 3.8 & 3.8 \\
\hline Quality factor & $167 f^{0.47}$ & $400 f^{0.48}$ & $372 f^{0.72}$ \\
\hline Kappa & 0.02 & 0.02 & 0.02 \\
\hline Geometrical spreading & \multirow{3}{*}{\multicolumn{3}{|c|}{$\begin{array}{c}1 / R(R<100 \mathrm{~km}), 1 / R^{0.5}(R>100 \mathrm{~km}) \\
\text { Saragoni and Hart }(1974) \\
5 \%\end{array}$}} \\
\hline Windowing function & & & \\
\hline Damping & & & \\
\hline
\end{tabular}

* Source parameters have been adopted from Nath et al. (2010).

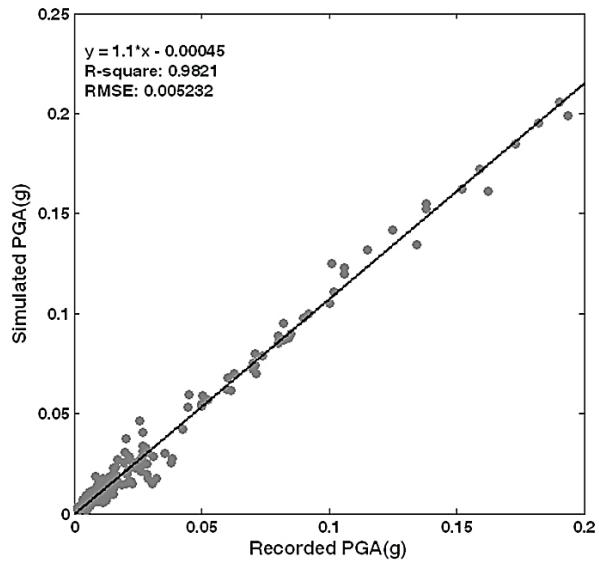

Figure 8. Scatterplot of the recorded and the synthesized PGA values for a wide magnitude range of $M_{\mathrm{W}} 3.9$ to 6.9 considered in all the three seismogenic sources, viz. the Bengal Basin, the eastcentral Himalaya and Northeast India.

Northeast India, and the IIT Kharagpur Broadband Seismological Observatory have been combined with the simulated ones. There are several algorithms available for ground motion synthesis. However, finite-fault stochastic method is considered to be best suited over a large fault rupture distance and the source characteristics for near-field approximation. In order to create a strong ground motion database, we simulated earthquakes of $M_{\mathrm{w}} 3.5$ to the maximum credible earthquake magnitude in the three tectonic provinces, namely the east-central Himalaya, the Bengal Basin and Northeast India, at $M_{\mathrm{w}} 0.2$ intervals with the source functions given in Table 4 and using the EXSIM stochastic simulation package developed by Motazedian and Atkinson (2005). Figure 7 exhibits a satisfactory agreement between the recorded and the simulated acceleration spectra of (1) the 13 December 2005 earthquake of $M_{\mathrm{w}} 4.0$ and the 6 February 2008 earthquake of $M_{\mathrm{w}} 4.9$ both recorded at IIT Kharagpur Broadband Seismological Observatory for the Bengal Basin seismogenic source (Fig. 7a and b); (2) the 18 September 2011 Sikkim earthquake of $M_{\mathrm{w}} 6.9$ recorded at Gangtok and Siliguri strong motion stations of DSSMN for the east-central Himalaya seismogenic source (Fig. 7c and d); (3) the 18 August 2009 Myanmar-India border earthquake of $M_{\mathrm{W}} 5.6$ recorded at Guwahati; and (4) the 4 February 2011 Myanmar-India border earthquake of $M_{\mathrm{w}} 6.4$ recorded at Jowai strong motion station of PESMOS for the Northeast India seismogenic source (Fig. 7e and f). Furthermore, a scatterplot shown in Fig. 8 between the recorded and the synthesized PGA values for a wide magnitude range of $M_{\mathrm{w}} 3.9$ to 6.9 considering all the three seismogenic sources, viz. the Bengal Basin, the east-central Himalaya and Northeast India, depicts a $1: 1$ correspondence, establishing the efficacy of earthquake synthesis and its utility in conjunction with the recorded ones in the creation of a significant strong ground motion database for working out the next-generation attenuation (NGA) models in the present study for probabilistic seismic hazard assessment of the region. Thereupon, nonlinear regression analyses were performed for different shaking parameters, $Y$ (i.e., PGA, PGV and PSA at different periods), following least-squares error minimization to estimate the coefficients of NGA models following Atkinson and Boore (2006) and Campbell and Bozorgnia (2003) as given in Eqs. (5) and (6), respectively, for the three major tectonic provinces, viz. the east-central Himalaya, the Bengal Basin and Northeast India.

a. The Atkinson and Boore (2006) (BA 06) model:

$$
\begin{aligned}
\log Y & =C_{1}+C_{2} M+C_{3} M^{2}+\left(C_{4}+C_{5} M\right) f_{1} \\
& +\left(C_{6}+C_{7} M\right) f_{2}+\left(C_{8}+C_{9} M\right) f_{0}+C_{10} R_{\mathrm{cd}},
\end{aligned}
$$

where 
Table 5. Regression coefficients considering the Atkinson and Boore (2006) (BA 06) NGA model for three tectonic regimes.

\begin{tabular}{|c|c|c|c|c|c|c|c|c|c|c|c|}
\hline PSA (s) & $C_{1}$ & $C_{2}$ & $C_{3}$ & $C_{4}$ & $C_{5}$ & $C_{6}$ & $C_{7}$ & $C_{8}$ & $C_{9}$ & $C_{10}$ & $\operatorname{SD}(\delta)$ \\
\hline \multicolumn{12}{|c|}{ East-central Himalaya source } \\
\hline 0.05 & 0.628 & 0.798 & -0.049 & -1.256 & 0.061 & -1.767 & 0.254 & 0.539 & -0.198 & -0.0039 & 0.208 \\
\hline 0.08 & 0.680 & 0.753 & -0.043 & -0.970 & 0.030 & -1.535 & 0.301 & 0.514 & -0.181 & -0.0047 & 0.257 \\
\hline 0.1 & 0.919 & 0.730 & -0.044 & -1.286 & 0.070 & -2.480 & 0.315 & 0.337 & -0.147 & -0.0036 & 0.205 \\
\hline 0.2 & 1.080 & 0.717 & -0.049 & -1.388 & 0.112 & -2.153 & 0.351 & 0.806 & -0.156 & -0.0049 & 0.175 \\
\hline 0.3 & 1.073 & 0.730 & -0.050 & -2.093 & 0.201 & -1.070 & 0.218 & -0.110 & -0.040 & -0.0042 & 0.160 \\
\hline 0.5 & 0.114 & 0.954 & -0.065 & -2.159 & 0.209 & -1.222 & 0.231 & 0.884 & -0.185 & -0.0039 & 0.159 \\
\hline 1 & -1.306 & 1.281 & -0.089 & -2.309 & 0.231 & -0.785 & 0.199 & 0.826 & -0.182 & -0.0036 & 0.164 \\
\hline 2 & -4.666 & 2.061 & -0.138 & -2.343 & 0.220 & -0.093 & 0.112 & 0.952 & -0.207 & -0.0035 & 0.157 \\
\hline 5 & -8.522 & 2.741 & -0.166 & -2.120 & 0.194 & -0.080 & 0.099 & 0.979 & -0.217 & -0.0035 & 0.156 \\
\hline PGA & 0.724 & 0.674 & -0.044 & -1.070 & 0.074 & -1.510 & 0.281 & 2.052 & -0.357 & -0.0054 & 0.201 \\
\hline PGV & -0.669 & 0.840 & -0.049 & -1.898 & 0.129 & -2.107 & 0.389 & 0.085 & -0.112 & -0.004 & 0.117 \\
\hline \multicolumn{12}{|c|}{ Bengal Basin source } \\
\hline 0.05 & 3.428 & 0.221 & -0.033 & -2.828 & 0.328 & -0.936 & 0.231 & -2.128 & 0.263 & -0.0053 & 0.131 \\
\hline 0.08 & 3.368 & 0.206 & -0.030 & -2.701 & 0.319 & 1.569 & -0.040 & -2.189 & 0.291 & -0.0059 & 0.132 \\
\hline 0.1 & 3.159 & 0.272 & -0.029 & -2.666 & 0.291 & 0.426 & 0.020 & -2.002 & 0.232 & -0.0051 & 0.128 \\
\hline 0.2 & 3.081 & 0.296 & -0.031 & -2.725 & 0.308 & 1.260 & -0.014 & -2.076 & 0.213 & -0.0057 & 0.142 \\
\hline 0.3 & 2.705 & 0.304 & -0.028 & -2.449 & 0.274 & 1.107 & 0.022 & -2.086 & 0.246 & -0.0054 & 0.124 \\
\hline 0.5 & 2.095 & 0.396 & -0.032 & -2.476 & 0.278 & 1.397 & -0.026 & -2.174 & 0.232 & -0.0051 & 0.137 \\
\hline 1 & 1.148 & 0.580 & -0.045 & -2.443 & 0.274 & 1.163 & -0.022 & -2.445 & 0.292 & -0.0045 & 0.142 \\
\hline 2 & -1.622 & 0.942 & -0.049 & -2.205 & 0.235 & 1.107 & -0.021 & -2.224 & 0.271 & -0.0041 & 0.143 \\
\hline 5 & -1.726 & 0.862 & -0.047 & -2.280 & 0.254 & 1.099 & -0.025 & -2.290 & 0.289 & -0.0042 & 0.181 \\
\hline PGA & 0.515 & 0.614 & -0.042 & -1.041 & 0.107 & -1.090 & 0.204 & 2.977 & -0.406 & -0.0063 & 0.153 \\
\hline PGV & 1.543 & 0.275 & -0.027 & -2.692 & 0.294 & 0.627 & 0.057 & 0.085 & -0.069 & -0.0048 & 0.171 \\
\hline \multicolumn{12}{|c|}{ Northeast India source } \\
\hline 0.05 & 0.770 & 0.650 & -0.032 & -1.077 & 0.060 & 0.592 & 0.141 & 0.090 & -0.098 & -0.0069 & 0.112 \\
\hline 0.08 & 0.666 & 0.662 & -0.032 & -0.917 & 0.039 & 0.822 & 0.095 & 0.214 & -0.121 & -0.006 & 0.112 \\
\hline 0.1 & 0.698 & 0.666 & -0.031 & -1.016 & 0.047 & 0.860 & 0.088 & 0.337 & -0.147 & -0.0059 & 0.108 \\
\hline 0.2 & 0.789 & 0.676 & -0.032 & -1.028 & 0.046 & 0.494 & 0.086 & 0.606 & -0.166 & -0.0058 & 0.116 \\
\hline 0.3 & 0.703 & 0.721 & -0.039 & -1.121 & 0.058 & 0.298 & 0.088 & 0.610 & -0.159 & -0.0054 & 0.109 \\
\hline 0.5 & 0.470 & 0.730 & -0.032 & -1.283 & 0.054 & 0.654 & 0.045 & 0.388 & -0.175 & -0.0049 & 0.116 \\
\hline 1 & -0.325 & 0.751 & -0.035 & -1.163 & 0.080 & 0.483 & 0.068 & 0.826 & -0.162 & -0.0044 & 0.161 \\
\hline 2 & -0.609 & 0.581 & -0.018 & -0.966 & 0.061 & 0.463 & 0.071 & 0.952 & -0.177 & -0.0041 & 0.227 \\
\hline 5 & -0.683 & 0.521 & -0.011 & -1.055 & 0.051 & 0.710 & -0.068 & -0.179 & -0.077 & -0.0034 & 0.138 \\
\hline PGA & 0.743 & 0.680 & -0.040 & -1.270 & 0.073 & -1.460 & 0.226 & 0.446 & -0.122 & -0.0041 & 0.378 \\
\hline PGV & -0.423 & 0.731 & -0.045 & -1.749 & 0.146 & 0.202 & 0.223 & 0.085 & -0.069 & -0.0056 & 0.116 \\
\hline
\end{tabular}

$f_{0}=\max \left(\log \left(R_{0} / R_{\mathrm{cd}}\right), 0\right) ; f_{1}=\min \left(\log R_{\mathrm{cd}}, \log R_{1}\right)$,

$f_{2}=\max \left(\log \left(R_{\mathrm{cd}} / R_{2}\right), 0\right) ; R_{0}=10 ; R_{1}=70 ; R_{2}=140$.

" $M$ " is the moment magnitude and " $R_{\mathrm{cd}}$ " is the closest distance to the fault. The obtained regression coefficients for the three main tectonic provinces using this NGA model (Eq. 5) are given in Table 5.

b. The Campbell and Bozorgnia (2003) (CB 03) model

$$
\begin{aligned}
\ln Y & =c_{1}+f_{1}\left(M_{\mathrm{w}}\right)+c_{4} \ln \sqrt{f_{2}\left(M_{\mathrm{w}}, r_{\text {seis }}, S\right)} \\
& +f_{3}(F)+f_{4}(S),
\end{aligned}
$$

where

$$
\begin{aligned}
& f_{1}\left(M_{\mathrm{W}}\right)=c_{2} M_{\mathrm{W}}+c_{3}\left(8.5-M_{\mathrm{W}}\right)^{2}, \\
& f_{2}\left(M_{\mathrm{W}}, r_{\text {seis }}, S\right)=r_{\text {seis }}^{2}+g(S)^{2} \\
& \left(\exp \left[c_{8} M_{\mathrm{W}}+c_{9}\left(8.5-M_{\mathrm{W}}\right)^{2}\right]\right)^{2}, \\
& g(S)=c_{5}+c_{6}\left(S_{\mathrm{VFS}}+S_{\mathrm{SR}}\right)+c_{7} S_{\mathrm{FR}}, \\
& f_{3}(F)=c_{10} F_{\mathrm{RV}}+c_{11} F_{\mathrm{TH}}, \\
& f_{4}(S)=c_{12} S_{\mathrm{VFS}}+c_{13} S_{\mathrm{SR}}+c_{14} S_{\mathrm{FR}} .
\end{aligned}
$$

$S_{\mathrm{VFS}}=1$ (very firm soil), $S_{\mathrm{SR}}=1$ (soft rock), $S_{\mathrm{FR}}=1$ (firm rock), $S_{\mathrm{VFS}}=S_{\mathrm{SR}}=S_{\mathrm{FR}}=0$ (firm soil), $F_{\mathrm{TH}}=1$ (thrust faulting), $\quad F_{\mathrm{RV}}=1$ (reverse), $\quad F_{\mathrm{RV}}=F_{\mathrm{TH}}=0$ (strike slip and normal). $M_{\mathrm{W}}$ represents moment 
Table 6. Regression coefficients considering the Campbell and Bozorgnia (2003) (CB 03) NGA model for three tectonic regimes.

\begin{tabular}{|c|c|c|c|c|c|c|c|c|c|c|c|c|c|c|c|}
\hline PSA (s) & $C_{1}$ & $C_{2}$ & $C_{3}$ & $C_{4}$ & $C_{5}$ & $C_{6}$ & $C_{7}$ & $C_{8}$ & $C_{9}$ & $C_{10}$ & $C_{11}$ & $C_{12}$ & $C_{13}$ & $C_{14}$ & $\mathrm{SD}(\delta)$ \\
\hline \multicolumn{16}{|c|}{ East-central Himalaya source } \\
\hline 0.05 & -3.104 & 0.970 & -0.034 & -1.547 & 0.0106 & -0.0039 & 0.052 & 0.809 & 0.084 & 0.479 & 0.436 & -0.144 & 0.088 & 0.242 & 0.287 \\
\hline 0.08 & -3.046 & 0.865 & 0.064 & -1.251 & 0.1221 & -0.0051 & -0.063 & 0.710 & 0.041 & 0.203 & 0.292 & -0.151 & 0.143 & -0.238 & 0.281 \\
\hline 0.1 & -3.133 & 0.882 & 0.063 & -1.231 & 0.1449 & -0.0051 & -0.079 & 0.719 & 0.034 & 0.305 & 0.372 & -0.142 & 0.196 & -0.289 & 0.279 \\
\hline 0.2 & -2.902 & 0.861 & 0.066 & -1.261 & 0.1395 & -0.0045 & -0.041 & 0.654 & 0.045 & 0.570 & 0.522 & -0.146 & 0.247 & -0.300 & 0.273 \\
\hline 0.3 & -2.614 & 0.952 & 0.064 & -1.459 & 0.128 & -0.0003 & -0.025 & 0.751 & 0.040 & 0.290 & 0.334 & -0.123 & 0.302 & -0.238 & 0.372 \\
\hline 0.5 & -3.122 & 0.742 & -0.109 & -1.070 & 0.2801 & -0.0003 & -0.251 & 0.791 & -0.140 & 0.474 & 0.518 & -0.123 & 0.294 & -0.070 & 0.537 \\
\hline 1 & -3.689 & 0.780 & -0.110 & -1.059 & 0.2716 & 0 & -0.206 & 0.788 & -0.176 & 0.326 & 0.335 & -0.072 & 0.257 & -0.239 & 0.492 \\
\hline 2 & -4.013 & 0.721 & -0.142 & -1.153 & 0.294 & 0 & -0.226 & 0.729 & -0.168 & 0.414 & 0.445 & -0.121 & 0.246 & -0.234 & 0.360 \\
\hline 5 & -4.847 & 0.757 & -0.129 & -1.243 & 0.2807 & 0 & -0.214 & 0.726 & -0.170 & 0.275 & 0.299 & -0.151 & 0.149 & -0.204 & 0.430 \\
\hline PGA & -3.777 & 1.101 & 0.037 & -1.586 & 0.0108 & -0.005 & -0.096 & 0.759 & 0.108 & 0.544 & 0.536 & -0.123 & -0.082 & -0.293 & 0.352 \\
\hline PGV & -0.781 & 1.134 & 0.030 & -1.272 & 0.0361 & -0.005 & -0.017 & 0.822 & 0.149 & 0.343 & 0.351 & -0.123 & 0.476 & -0.625 & 0.374 \\
\hline \multicolumn{16}{|c|}{ Bengal Basin source } \\
\hline 0.05 & -4.732 & 1.040 & 0.046 & -1.212 & 0.0458 & -0.005 & -0.080 & 0.784 & 0.096 & 0.243 & 0.333 & -0.150 & -0.272 & -0.284 & 0.244 \\
\hline 0.08 & -2.852 & 0.837 & 0.056 & -1.271 & 0.1261 & -0.005 & -0.068 & 0.779 & 0.044 & 0.243 & 0.333 & -0.150 & -0.082 & -0.294 & 0.335 \\
\hline 0.1 & -2.582 & 0.812 & 0.039 & -1.258 & 0.1464 & -0.009 & -0.060 & 0.674 & 0.093 & 0.224 & 0.313 & -0.146 & -0.184 & -0.289 & 0.329 \\
\hline 0.2 & -3.296 & 0.950 & 0.021 & -1.276 & 0.103 & -0.014 & -0.036 & 0.746 & 0.059 & 0.296 & 0.342 & -0.148 & -0.288 & -0.264 & 0.318 \\
\hline 0.3 & -4.377 & 0.987 & 0.004 & -1.192 & 0.0208 & -0.002 & -0.004 & 0.888 & 0.068 & 0.406 & 0.479 & -0.123 & 0.229 & -0.142 & 0.390 \\
\hline 0.5 & -4.694 & 1.027 & 0.029 & -1.164 & 0.0228 & -0.007 & -0.046 & 0.874 & 0.100 & 0.216 & 0.279 & -0.173 & -0.108 & -0.279 & 0.336 \\
\hline 1 & -3.440 & 0.762 & -0.036 & -1.175 & 0.0298 & 0 & -0.065 & 0.786 & 0.097 & 0.329 & 0.338 & -0.073 & -0.149 & -0.235 & 0.306 \\
\hline 2 & -4.737 & 0.757 & -0.094 & -0.939 & 0.0182 & 0 & -0.041 & 0.854 & 0.012 & 0.060 & 0.064 & -0.124 & -0.212 & -0.212 & 0.277 \\
\hline 5 & -5.777 & 0.733 & -0.142 & -0.857 & 0.0124 & 0 & -0.019 & 0.876 & 0.126 & 0.061 & 0.057 & -0.054 & -0.597 & -0.225 & 0.225 \\
\hline PGA & -4.734 & 1.027 & 0.031 & -1.294 & 0.0228 & -0.002 & -0.092 & 0.744 & 0.110 & 0.406 & 0.479 & -0.123 & -0.108 & -0.279 & 0.356 \\
\hline PGV & -0.540 & 1.086 & 0.023 & -1.209 & 0.0408 & -0.005 & -0.015 & 0.828 & 0.144 & 0.343 & 0.351 & -0.123 & -0.645 & -0.796 & 0.373 \\
\hline \multicolumn{16}{|c|}{ Northeast India source } \\
\hline 0.05 & -2.184 & 0.767 & 0.036 & -1.347 & 0.0896 & -0.004 & -0.049 & 0.789 & 0.088 & 0.274 & 0.334 & -0.140 & 0.678 & -0.231 & 0.269 \\
\hline 0.08 & -2.276 & 0.800 & 0.065 & -1.348 & 0.114 & -0.005 & -0.067 & 0.790 & 0.057 & 0.302 & 0.392 & -0.150 & 0.234 & -0.222 & 0.269 \\
\hline 0.1 & -2.403 & 0.825 & 0.062 & -1.295 & 0.1239 & -0.009 & -0.059 & 0.709 & 0.068 & 0.201 & 0.290 & -0.146 & 0.485 & -0.250 & 0.264 \\
\hline 0.2 & -2.152 & 0.840 & 0.034 & -1.346 & 0.0925 & -0.014 & -0.041 & 0.743 & 0.085 & 0.374 & 0.320 & -0.148 & 0.456 & -0.280 & 0.256 \\
\hline 0.3 & -2.398 & 0.899 & 0.030 & -1.470 & 0.0906 & -0.002 & -0.047 & 0.821 & 0.061 & 0.482 & 0.455 & -0.123 & 0.458 & -0.213 & 0.346 \\
\hline 0.5 & -2.182 & 0.798 & -0.036 & -1.324 & 0.0806 & -0.002 & -0.047 & 0.791 & 0.081 & 0.226 & 0.327 & -0.123 & 0.494 & -0.257 & 0.445 \\
\hline 1 & -3.260 & 0.810 & -0.052 & -1.211 & 0.084 & 0 & -0.046 & 0.801 & 0.095 & 0.243 & 0.252 & -0.073 & 0.335 & -0.251 & 0.456 \\
\hline 2 & -4.129 & 0.585 & -0.096 & -0.903 & 0.0788 & 0 & -0.047 & 0.750 & 0.086 & 0.403 & 0.407 & -0.124 & 0.556 & -0.244 & 0.336 \\
\hline 5 & -4.797 & 0.578 & -0.099 & -0.954 & 0.06107 & 0 & -0.092 & 0.766 & 0.068 & 0.290 & 0.286 & -0.054 & 0.153 & -0.215 & 0.336 \\
\hline PGA & -3.230 & 0.870 & 0.040 & -1.311 & 0.0609 & 0 & -0.096 & 0.781 & 0.095 & 0.143 & 0.152 & -0.073 & 0.335 & -0.251 & 0.353 \\
\hline PGV & -1.455 & 1.071 & 0.052 & -1.072 & 0.037 & -0.005 & -0.047 & 0.863 & 0.091 & 0.243 & 0.251 & -0.123 & 0.231 & -0.241 & 0.357 \\
\hline
\end{tabular}

magnitude and $r_{\text {seis }}$ represents the closest distance to seismogenic rupture. According to Campbell and Bozorgnia (2003), the nonlinear site effects inherent in large ground motion on firm soil do not permit a significant increase in ground motion over the hanging wall effect. Moreover, the hanging wall effect dies out for $r_{\text {seis }}<8 \mathrm{~km}$, or sooner if $r_{j b} \geq 5 \mathrm{~km}$ or $\delta \geq 70^{\circ}$. Hence, in the present scenario, the hanging wall effect is not considered and the prediction equation has been modified after Campbell and Bozorgnia (2003) to generate a NGA model suitable for the entire West Bengal region. The obtained regression coefficients for the three main tectonic provinces using this NGA model (Eq. 6) are given in Table 6. For establishing further efficacy of the analyses performed in the present study, we generated a comparative plot of the predicted, recorded and simulated PGA values for the three aforesaid dominant seismogenic sources, as shown in Fig. 9, which exhibits a satisfactory agreement amongst all the three values. The regression models for PGA and PSA have been val- idated using an analysis of residuals:

residual $=\log _{10}\left(\frac{Y_{\mathrm{os}}}{Y_{\mathrm{p}}}\right)$

where $Y_{\mathrm{os}}$ is the recorded and simulated PGA/PSA and $Y_{\mathrm{p}}$ is the estimated PGA/PSA from the empirical attenuation relation. Residual plots for PGA as a function of fault distance for the three seismogenic sources are shown in Fig. 10. It is evident that the residuals have a zero mean and are uncorrelated with respect to fault distance. A residual analysis of PGA and PSA of the NGA models predicted in the present investigation is unbiased with respect to both the magnitude and fault distance, and hence can be used along with other existing prediction equations available for the region as well as those available for a similar tectonic setup in a logic tree framework for seismic hazard assessment of Kolkata. 
Table 7. Selected ground motion prediction equations for PSHA in the present study.

\begin{tabular}{ll}
\hline \multicolumn{2}{c}{ Selected ground motion prediction equations (GMPEs) } \\
\hline Tectonic province & Reference and code in parentheses \\
\hline East-central Himalaya & $\begin{array}{l}\text { Campbell and Bozorgnia (2003) (CB 03), Atkinson and Boore } \\
\text { (2006) (BA 06), Sharma et al. (2009) (SHAR 09), Toro (2002) } \\
\\
\text { (TORO 02), Campbell and Bozorgnia (2008) (CB 08) }\end{array}$ \\
\hline Bengal Basin & Campbell and Bozorgnia (2003) (CB 03), Atkinson and Boore \\
& (2006) (BA 06), Raghukanth and Iyengar (2007) (RI 07), Toro \\
& (2002) (TORO 02) \\
\hline Northeast India & Campbell and Bozorgnia (2003) (CB 03), Atkinson and Boore \\
& (2006) (BA 06), Nath et al. (2012) (NATH 12) (shallow and deep \\
& crust), Youngs et al. (1997) (YOUNGS 97), Campbell and \\
Bozorgnia (2008) (CB 08)
\end{tabular}
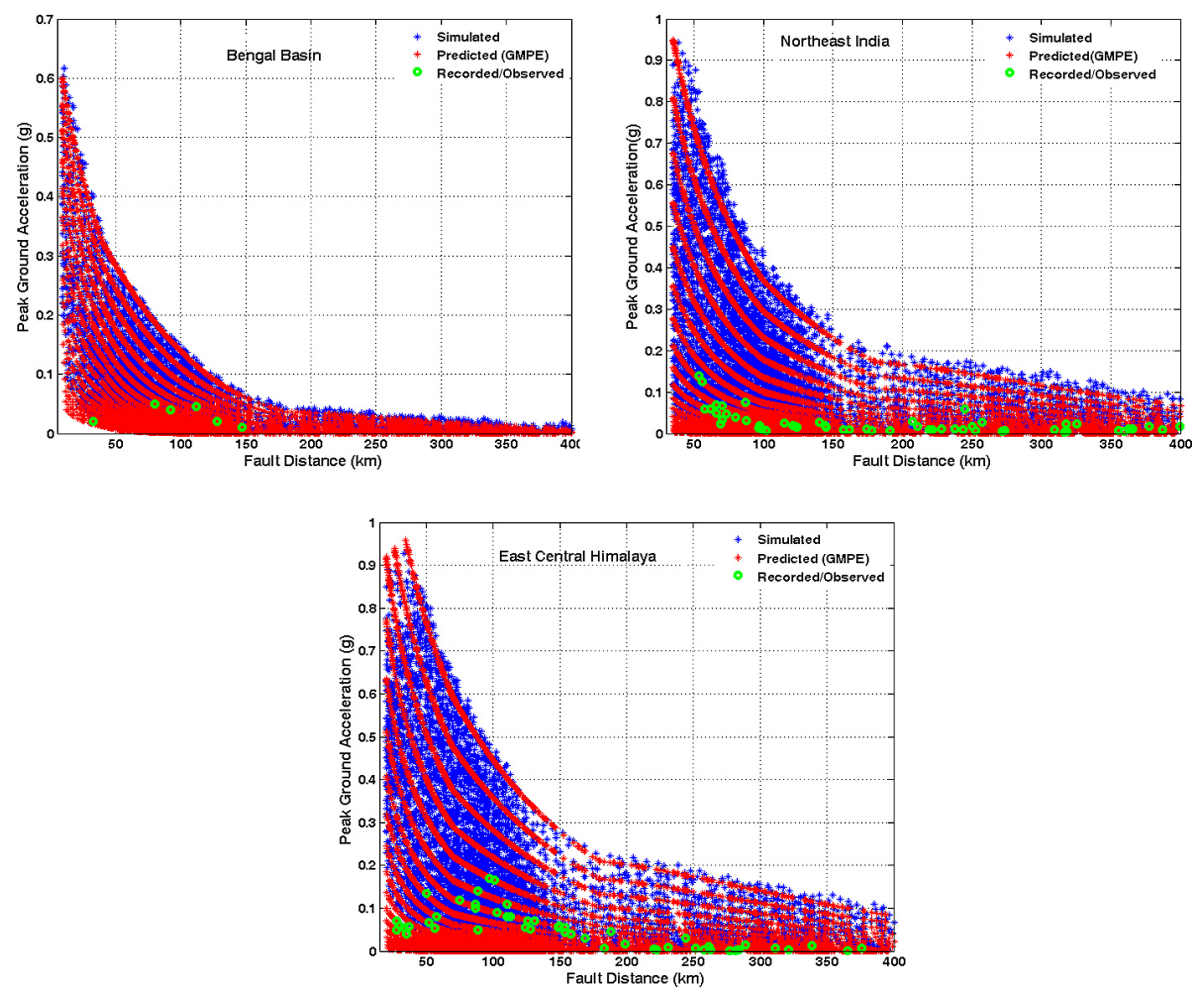

Figure 9. The blue dots represent the simulated PGA, the red dots represent the estimated PGA from the prediction equation, and the green dots represent the recorded PGA for three dominant seismic sources.

We adopted a total of 14 Ground Motion Prediction Equations (GMPEs) as given in Table 7 for hazard computations in the region, whereas the coefficients for the additional $8 \mathrm{GM}$ PEs have been used as reported in the original publications. The GMPEs are selected according to the assessment criterion of Nath and Thingbaijam (2011b). Appropriate GMPE weight has been assigned based on the seismotectonism and geology of the province, with maximum weight being assigned to the regressed NGAs developed as a part of the present study.

\subsection{PSHA computational model}

A synoptic probabilistic seismic hazard model of Kolkata is generated at engineering bedrock $\left(V_{\mathrm{s}}^{30} \sim 760 \mathrm{~m} \mathrm{~s}^{-1}\right)$. The basic methodology of probabilistic seismic hazard analysis involves computation of ground motion thresholds that are exceeded with a mean return period of, for example, 475 years/2475 years at a particular site of interest. The effects of all the earthquakes of different sizes occurring at various locations for all the seismogenic sources at various 

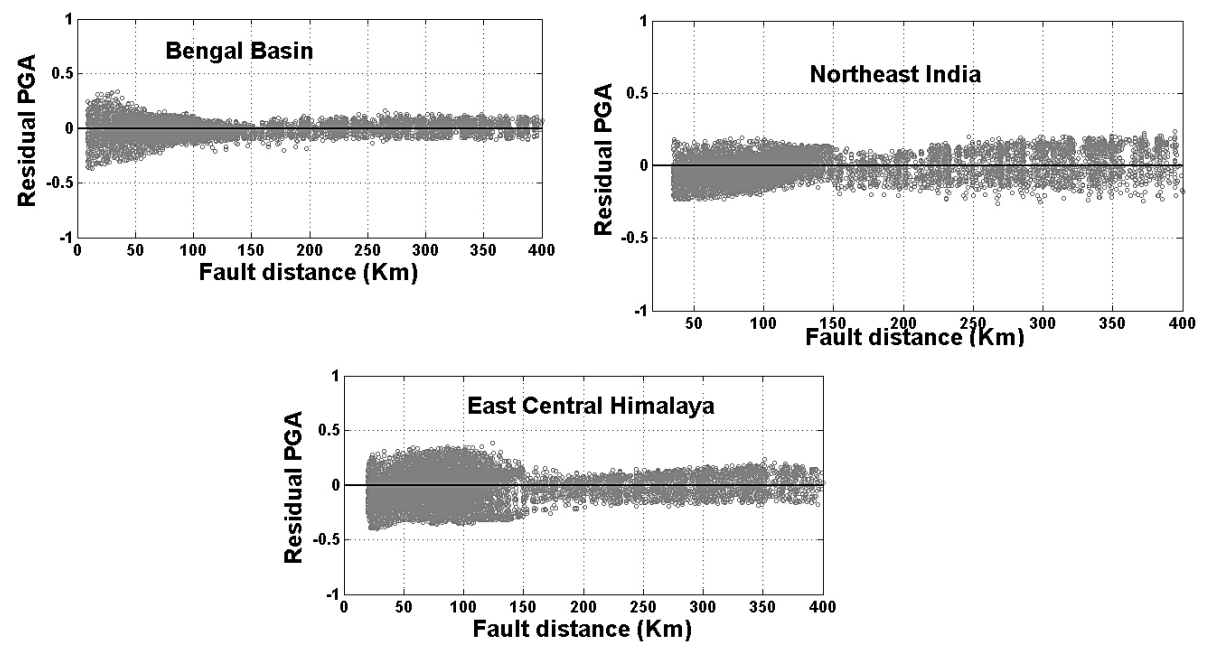

Figure 10. Residuals of PGA with respect to fault distance for the Bengal Basin, Northeast India and east-central Himalaya seismogenic sources.

probabilities of occurrences are integrated into one curve that shows the probability of exceeding different levels of a ground motion parameter at the site during a specified time period. The computational formulation as developed by Cornell (1968), Esteva (1970) and McGuire (1976) is given as

$$
\begin{gathered}
\nu(a>A)=\sum_{i} \int_{\mathrm{m}} \int_{\mathrm{r}} \int_{\delta} \lambda_{i} P(a>A \mid m, r, \delta) f_{\mathrm{m}}(m) f_{\mathrm{r}}(r) \\
f_{\Delta}(\delta) d m d r d \delta
\end{gathered}
$$

where $v(a>A)$ is the annual frequency of exceedance of ground motion amplitude $A, \lambda$ is the annual activity rate for the $i$ th seismogenic source for a threshold magnitude, and function $P$ yields probability of the ground motion parameter $a$ exceeding $A$ for a given magnitude $m$ at source-to-site distance $r$. The corresponding probability density functions are represented by $f_{\mathrm{m}}(m), f_{\mathrm{r}}(r)$ and $f_{\Delta}(\delta)$. The probability density function for the magnitudes is generally derived from the GR relation (Gutenberg and Richter, 1944). The present implementation makes use of the density function given by Bender (1983) as

$f_{\mathrm{m}}(m)=\frac{\beta \exp \left[-\beta\left(m-m_{\min }\right)\right]}{1-\exp \left[-\beta\left(m_{\max }-m_{\min }\right)\right]}$,

where $\beta=b \ln (10)$ and $b$ refers to the $b$ value of GR relation. The distribution is bounded within a minimum magnitude $m_{\min }$ and a maximum magnitude $m_{\max } \cdot f_{\Delta}(\delta)$ is the probability density function (in lognormal distribution) associated with the standard deviation of the residuals in GMPE. $f_{\Delta}(\delta)$ also defines the epsilon $(\varepsilon)$ standard deviations of the ground motion from its median value through the prediction equation. The GMPEs are described as relationships between a ground motion parameter " $Y$ " (i.e., PGA, PGV or PSA at different periods), an earthquake magnitude " $M$ ", a source-to- site distance " $R$ ", and an uncertainty or residual $(\delta)$ through

$\ln (Y)=f(M, R)+\delta$

The ground motion uncertainty $\delta$ is modeled as a normal distribution with a standard deviation, $\sigma_{\ln , y}$. Hence the above equation can be expressed as

$\ln (Y)=f(M, R)+\varepsilon \sigma_{\ln , y}$,

where $\varepsilon$ is the normalized residual, which is also a normal distribution with a constant standard deviation, and $\sigma_{\ln , y}$ is the standard deviation associated with the GMPE. In the PSHA formulation as given in Eq. (8), standard deviation denoted by $\delta$ is basically the residual associated with each GMPE. The probability density function $f_{\Delta}(\delta)$ follows a lognormal distribution that can be expressed as

$f_{\Delta}(\delta)=\frac{1}{\sqrt{2 \pi} \sigma_{\ln , y}} \exp \left[-\frac{\left(\ln y-\ln y_{\mathrm{mr}}\right)^{2}}{2 \sigma_{\ln , y}^{2}}\right]$,

where $\ln y_{\mathrm{mr}}=f(M, R)$ is the functional form of the prediction model in terms of magnitude and distance. Ground motion variability constitutes aleatory uncertainty intrinsic to the definition of GMPEs and consequently to that of PSHA. Computations based only on the median ground motions ignoring the associated variability are known to underestimate the hazards, especially at low annual frequencies of exceedance (Bommer and Abrahamson, 2006). The value of $\varepsilon_{\text {max }}$ ranging from 2 to 4 has often been employed in probabilistic seismic hazard estimations (e.g., Marin et al., 2004). However, truncation at $\varepsilon_{\max }<3$ has been suggested to be inappropriate (e.g., Bommer and Abrahamson, 2006). In the present study, truncation at $\varepsilon_{\max }=4$ is considered to be pragmatic and implemented uniformly for all the GMPEs. 
The distance probability function $f_{\mathrm{r}}(r)$ represents the probability of occurrence of a given earthquake at a distance in the range $(r, r+d r)$. In the present analysis, instead of considering probability function for the source-to-site distance distinctively, we have implemented gridded-point locations within the source zone, where finite-fault ruptures are constructed based on the rupture dimensions estimated for each magnitude.

The hazard computation is performed using a Poisson occurrence model given by Eq. (13) below on grid points covering the entire study region at a spacing of $0.005^{\circ}$.

$P=1-e^{-\lambda t}$

where $\lambda$ is the rate of occurrence of the event (annual activity rate) and $t$ is the time period of exceedance. With this, the annual rate of exceedance for an event with $10 \%$ probability in 50 years is given by

$\lambda=-[\ln (1-0.1) / 50]=0.0021 / \mathrm{yr}$.

A logic tree framework depicted in Fig. 11 is employed in the computation at each site to incorporate multiple models in the source considerations, GMPEs and seismicity parameters. In the present study, the seismogenic sources, i.e., tectonic and layered polygonal sources, are assigned weights equal to 0.6 and 0.4 , respectively. The three derivatives for the threshold magnitude of $M_{\mathrm{w}} 3.5,4.5$ and 5.5 are assigned weights equal to $0.20,0.35$ and 0.45 , respectively. The seismicity model parameters, namely the annual rate of earthquakes $(\lambda(m))$ and $\beta$ pairs, are assigned weights of 0.36 , while the respective \pm 1 standard deviation receives weight equal to 0.32. Similar weight distribution is assigned for $m_{\max }$. The weights are allocated following the statistical rationale suggested by Grünthal and Wahlström (2006). In order to define appropriate weights, the percentage of probability mass in a normal distribution for the mean value and \pm 1 standard deviation is considered corresponding to the center of two equal halves. Figure 12 depicts seismic hazard curves for selected landmarks of Kolkata corresponding to PGA, PSA at 0.2 and $1 \mathrm{~s}$ at engineering bedrock. Both the 2 and $10 \%$ probability of exceedance levels in 50 years have been marked with horizontal dotted lines in the diagram. The spatial distribution of PGA in Kolkata presented in Fig. 13 for $10 \%$ probability of exceedance in 50 years at engineering bedrock shows a variation of 0.124 to $0.178 \mathrm{~g}$. The regions of Rajarhat, Newtown and Salt Lake are seen to have a higher hazard level, while a moderate hazard level is associated with the regions of Park Circus, Dhakuria, Kasba, Barabazar and Dharmatala. A low hazard level of around $0.12-0.13 \mathrm{~g}$ is observed in the southwestern part of Kolkata, encompassing areas of Behala, Metiabruz and Mahestala.

\section{Surface consistent and site-specific hazard attributions}

Site-specific hazard attribution necessitates (i) precise geomorphologic definition of the terrain, including the lithological characterization and sediment classification; (ii) in-depth surface geophysical and downhole geotechnical investigations for shallow shear wave velocity estimation and site classification following the National Earthquake Hazard Reduction Program (NEHRP), USGS and FEMA nomenclature; (iii) a site response analysis and probabilistic seismic hazard assessment at a surface-consistent level propagating the bedrock ground motion with $10 \%$ probability of exceedance in 50 years through a 1-D sediment column and performing equivalent linear analysis of an otherwise nonlinear system through DEEPSOIL (Hashash, 2009); and (iv) assessment of liquefaction potential index from in situ borehole geotechnical data and $N$ value/shear wave velocity profiles. To date, no evidence of any ground rupture in Kolkata due to the historical earthquakes affecting the terrain has been reported. In addition, following the earthquake ground effect postulations of Silva et al. (2008) and Reicherter et al. (2009), there is only a very remote possibility of the occurrence of a coseismic surface-rupture hazard in the city during the time span used in the present study with the probabilistic framework for $10 \%$ probability of exceedance in 50 years. Nonetheless, the utility of ground-rupture hazard mapping from histori$\mathrm{cal} /$ paleoseismic evidence and its integration with all the geological and seismological themes in the holistic seismic microzonation protocol is well conceived in the microzonation framework used in the present study.

\subsection{Geomorphology of Kolkata}

Kolkata overlies the Bengal Basin, which is formed by the Ganga-Brahmaputra river system and is also one of the largest deltas in the world. The basin consists of fluviomarine sediment of a pericratonic Tertiary basin. The surficial geology in and around Kolkata is rather uniform, and is characterized by the presence of $10-15 \mathrm{~m}$ of silty clay, below which relatively coarser sediments occur that consist of either silt or clay with kunkar or sand (Vaccari et al., 2011). Geomorphologically, it is a typical deltaic flat land with surface elevation ranging between 5.5 and $9.5 \mathrm{~m}$ a.m.s.l sloping mostly southward. Deltaic plains, interdistributary marshes, paleochannels, younger levees adjacent to the River Hoogly and older levees on both the sides of the old Adi Ganga are the important geomorphological units (Roy et al., 2012), as depicted in Fig. 14. Youd and Perkins (1978) classified the geomorphological units with affinity to high, moderate and low susceptibility to liquefaction, with the maximum likelihood in deltas, river channels and uncompacted artificial fills, whereas Ganapathy and Rajawat (2012) asserted abandoned river channel to be "likely" liquefiable. Thus, in Kolkata, all 


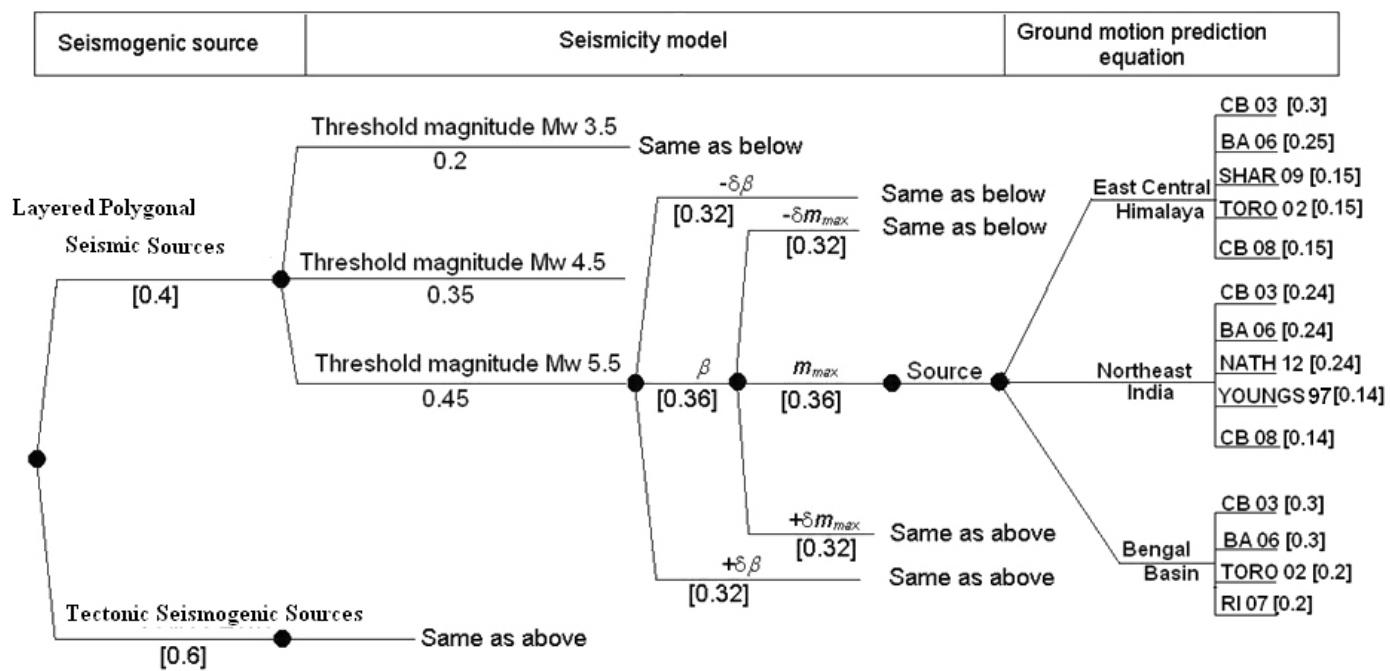

Figure 11. A logic tree formulation for probabilistic seismic hazard computation at each node of the region gridded at $0.005^{\circ} \times 0.005^{\circ}$ intervals.
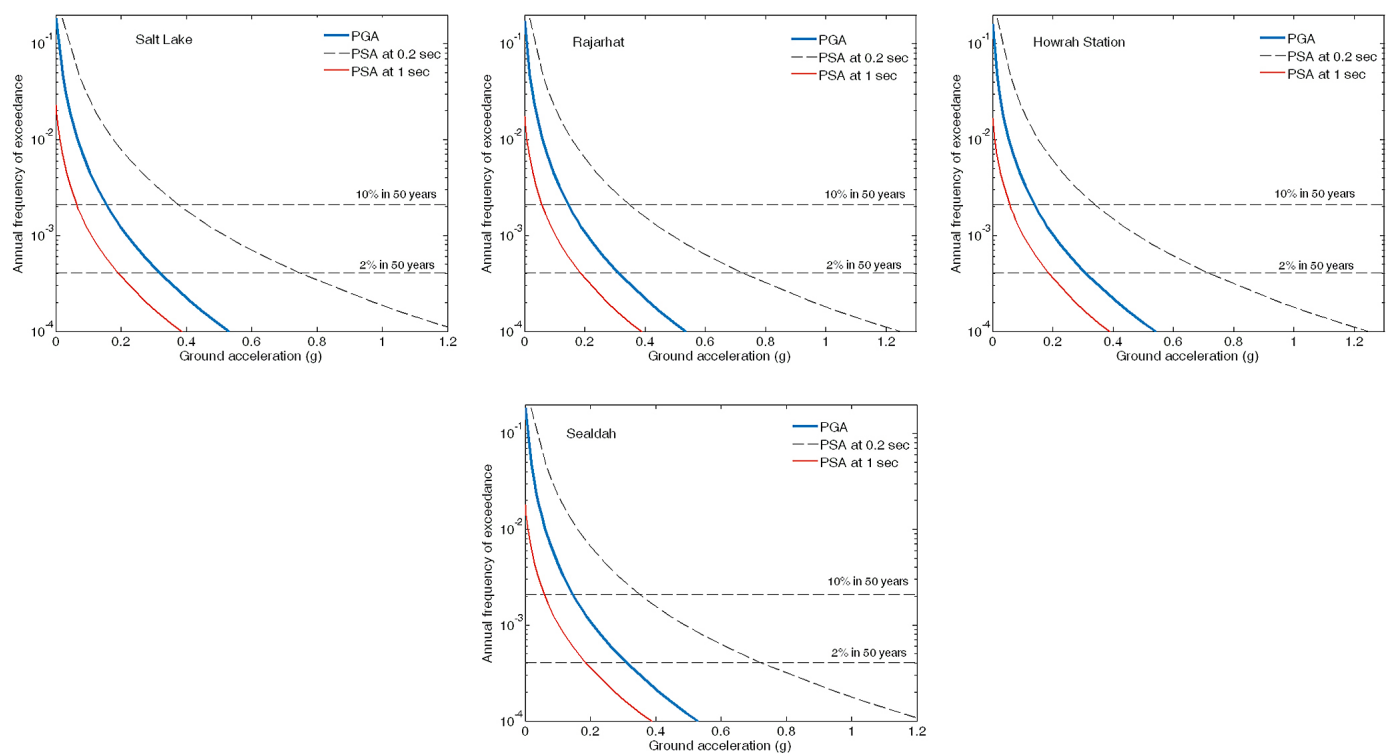

Figure 12. Annual frequency of exceedance vs. ground acceleration plots usually termed as seismic hazard curves for a few selected locations in Kolkata for peak and spectral accelerations at 0.2 and $1 \mathrm{~s}$ for a uniform firm rock site condition (compliant with $V_{\mathrm{s}}^{30} \sim 760 \mathrm{~m} \mathrm{~s}{ }^{-1}$ ). Both the 10 and $2 \%$ probabilities of exceedance in 50 years have been marked with horizontal dotted lines in each plot.

geomorphological units have potential liquefaction susceptibility during strong seismic shaking.

\subsection{Sediment classification in Kolkata}

Based on the proportions of sand, silt and clay-sized particles obtained from 350 boreholes in Kolkata as shown in Fig. 14, the bottom sediments have been classified according to Shepard's diagram (O'Malley, 2007), which is an example of a ternary diagram - a device for graphing a three-component system summing to $100 \%$ (Shepard, 1954). In this case, the components are the percentages of sand, silt and clay comprising a sediment sample. Each sediment sample plots as a point within or along the sides of the diagram, depending on its specific grain size composition. Using the borehole lithologs and the Shepard classification system, shallow sediment classification of Kolkata is performed that exhibits highly liquefiable sediments (Updike et al., 1988; Yamamuro and Hade, 1999), viz. sand, sand-silt-clay mixture, sandy clay, silty sand and silty clay up to about $\sim 5 \mathrm{~m}$ as shown in Fig. 15. 


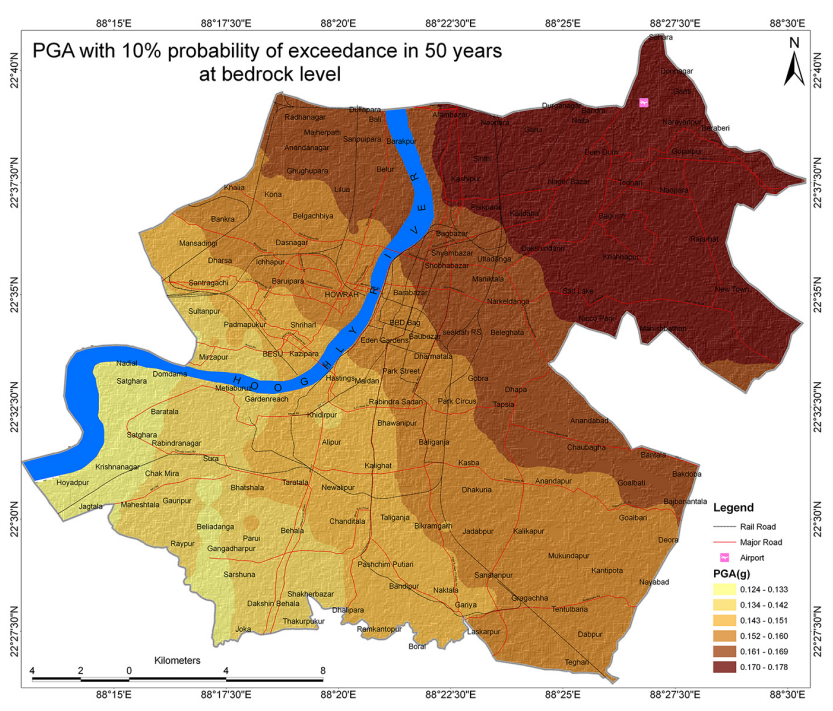

Figure 13. Spatial distribution of PGA in Kolkata with $10 \%$ probability of exceedance in 50 years at bedrock.

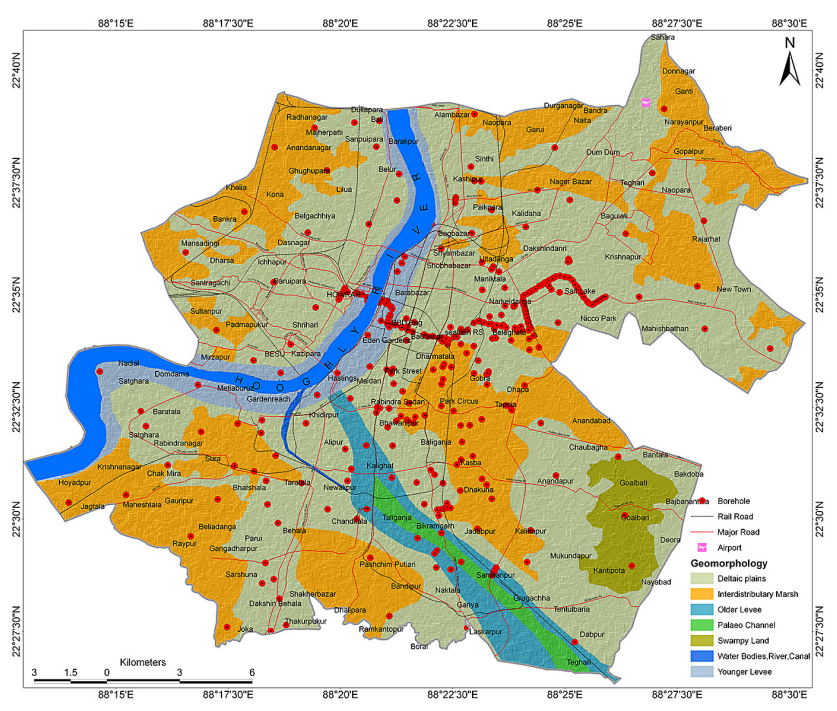

Figure 14. Geomorphology map of Kolkata highlighting the borehole locations where detailed geotechnical investigations have been carried out (total of 350 locations) for the purpose of site characterization.

\subsection{Shear wave velocity estimation and NEHRP site classification in Kolkata}

Effective shear wave velocity $\left(V_{\mathrm{s}}^{30}\right)$ for a $30 \mathrm{~m}$ soil column is one of the most important parameters used in the understanding of geotechnical earthquake engineering problems. One of the easiest ways to estimate $V_{\mathrm{s}}^{30}$ is to use an empirical relationship between Standard Penetration Test (SPT) " $N$ " values and shear wave velocities. Several empirical relations between SPT " $N$ " values and lithology are available (Nath and Thingbaijam, 2011a). A nonlinear regression be-

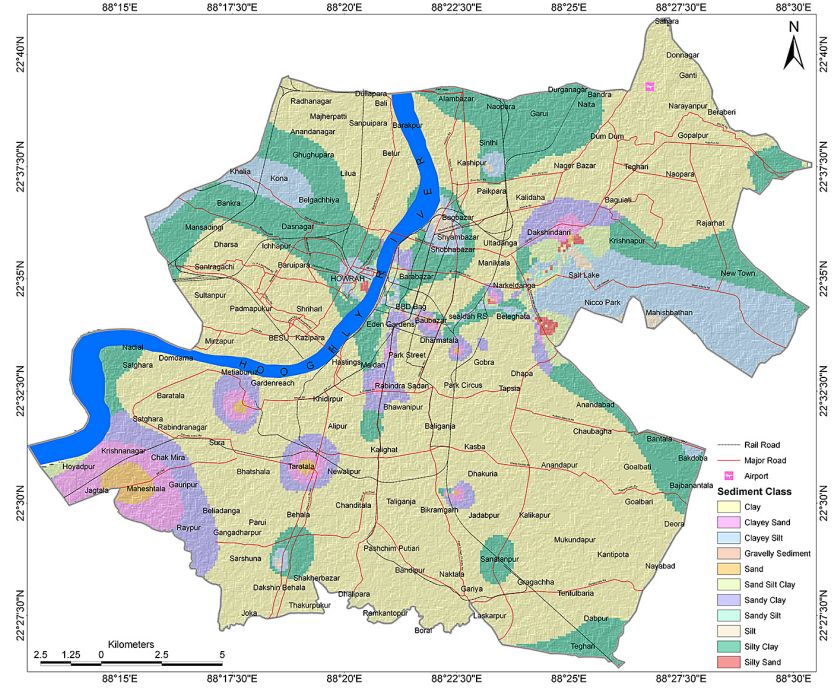

Figure 15. Top $\sim 5 \mathrm{~m}$ sediment classification from geotechnical parameters obtained from 350 boreholes in Kolkata.

tween the corrected SPT " $N$ " values and empirically derived average shear wave velocities of clay, sand and all types of soil for the city of Kolkata calibrated using in situ downhole shear wave velocity at 350 borehole locations yield the following relations:

$\begin{array}{ll}V_{\mathrm{s}}=97.86\left(N_{60}\right)^{0.308} & \text { clay } \\ V_{\mathrm{s}}=82.59\left(N_{60}\right)^{0.358} & \text { sand } \\ V_{\mathrm{s}}=87.54\left(N_{60}\right)^{0.345} & \text { all soil. }\end{array}$

The horizontal-to-vertical response curves obtained from microtremor survey reflect the geology and soil properties of the test site. Ambient noise data acquired using SYSCOM MR2000 at 1200 locations in the city have been processed using View2002 and GEOPSY software (www.geopsy.org) and inverted to authenticate the geotechnically derived 1D shear wave velocity model by comparing the theoretical horizontal-to-vertical spectral ratio (HVSR) to the observed ones. The Matlab code ModelHVSR developed by Herak (2008) has been used to invert HVSR curves for the estimation of 1-D $V_{\mathrm{s}}$ profiles at each investigation site. In situ downhole shear wave velocity profiling eventually benchmarks the $V_{\mathrm{s}}^{30}$ derived from surface geophysical techniques and SPT " $N$ " values. Figure 16 depicts a few microtremor records, the borehole lithology, the 1-D shear wave velocity from the SPT " $N$ " value, and $V_{\mathrm{s}}$ from in situ downhole shear wave seismic survey, as well as that obtained by HVSR inversion.

Site classification of Kolkata performed based on NEHRP, USGS and FEMA regulations places the city in D1 $\left(V_{\mathrm{s}}^{30}\right.$ : $\left.180-240 \mathrm{~m} \mathrm{~s}^{-1}\right)$, D2 $\left(V_{\mathrm{s}}^{30}: 240-300 \mathrm{~m} \mathrm{~s}^{-1}\right)$, D3 $\left(V_{\mathrm{s}}^{30}: 300-\right.$ $\left.360 \mathrm{~m} \mathrm{~s}^{-1}\right)$ and $\mathrm{E}\left(V_{\mathrm{s}}^{30}<180 \mathrm{~m} \mathrm{~s}^{-1}\right)$ classes, as shown in Fig. 17. From the diagram it is evident that the low-velocity site class $\mathrm{E}\left(V_{\mathrm{s}}^{30}<180 \mathrm{~m} \mathrm{~s}^{-1}\right)$ is related to alluvial debris 

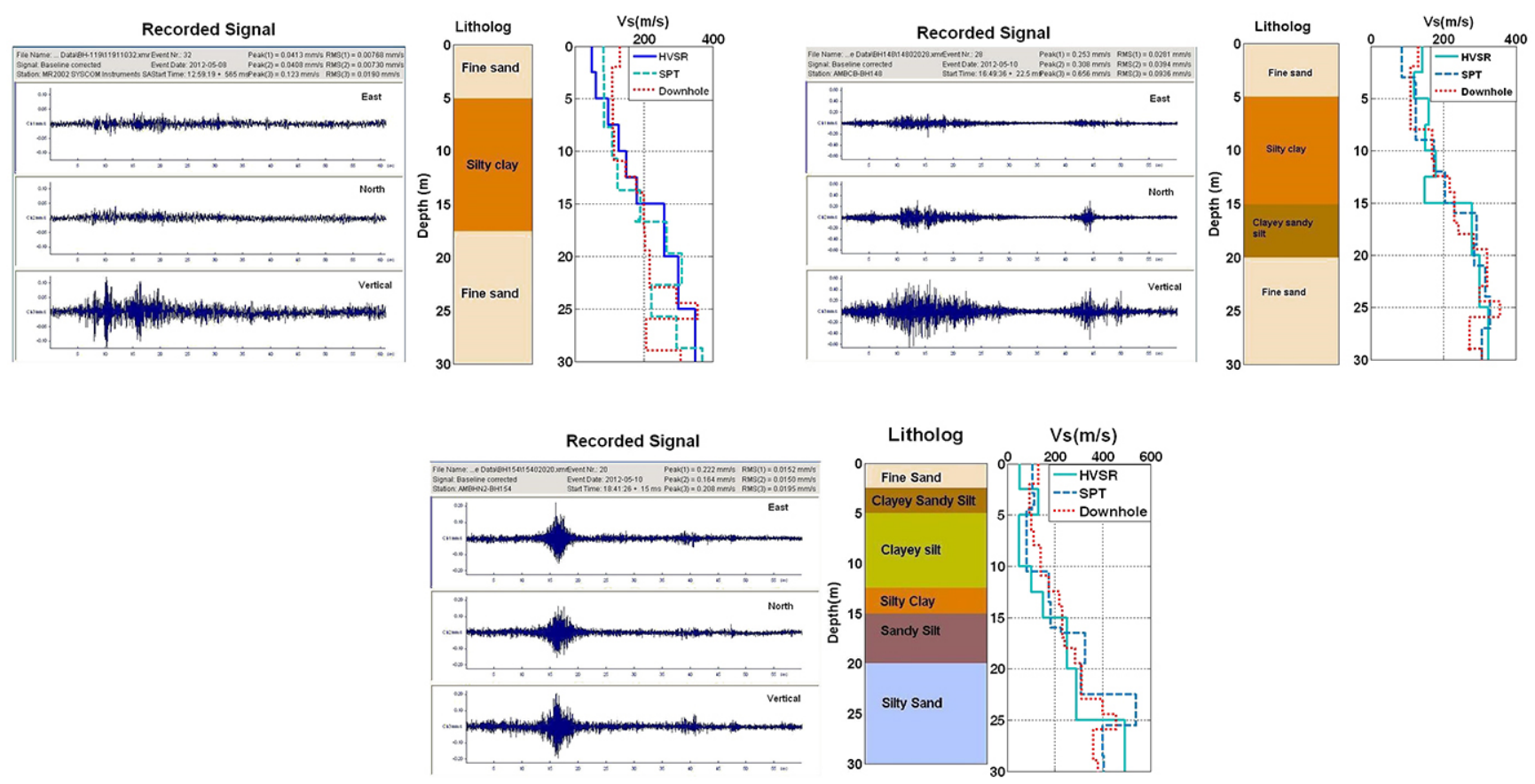

Figure 16. Representative ambient noise survey as "Recorded Signal", lithostratigraphy as "Lithology", and comparative 1-D shear wave velocity $\left(V_{\mathrm{S}}\right)$ models derived from empirical SPT formulations, HVSR inversion and in situ downhole shear wave seismic survey as $V_{\mathrm{S}}\left(m s^{-1}\right)$ at Rajarhat (top left panel), Salt Lake (top right panel) and Park Circus (bottom panel) in Kolkata for calibration at 350 borehole locations and 1200 ambient noise survey sites with $500 \mathrm{~m}$ spacing.

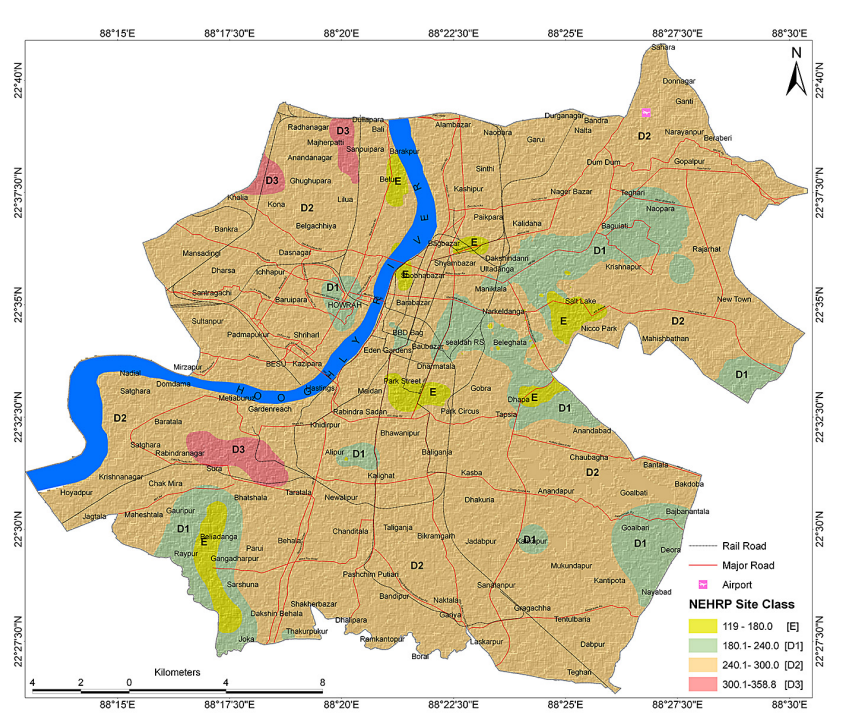

Figure 17. Site classification of Kolkata following NEHRP nomenclature. Site classes D1, D2, D3 and E have been identified in the terrain.

thick horizons with clayey silt. Site class D1 is identified in some parts of Mukundapur, Salt Lake, Narkeldanga, Sealdah and the southeastern part of the city, all of those being predominantly underlain by silty clay and sandy clay. Most of the areas classified as site class D2 are composed of deep stiff soil with varied sediment deposits of clay, sand and clayey sand. In contrast, site class D3 comprises very dense soil and soft rock, such as boulders, cobbles or near-surface fractured rocks.

\subsection{Site response and surface consistent probabilistic PGA/PSA}

The amplification of ground motion over soft sediments occurs fundamentally due to the impedance contrast between sediments and the underlying bedrock resulting in the trapping of seismic waves. Geotechnical parameters such as soil type, thickness of the layer, unit weight, Atterberg limits and shear wave velocity of the material have been used for the estimation of site effects by propagating the bedrock motion to the ground surface through a 1-D soil column using equivalent linear analysis of a nonlinear system. A $5 \%$ damping is used for all soil types while synthesizing the subsoil response for earthquake engineering purposes. The input time series obtained by inverse Fourier transform of the pseudo-spectral acceleration computed for $10 \%$ probability of exceedance in 50 years at engineering bedrock is used to model the nonlinear behavior of a $30 \mathrm{~m}$ soil column at 350 borehole locations with a precise 1-D $V_{\mathrm{s}}$ profile in order to generate site amplification and hence compute surface consistent PGA and PSA at each location. Figure 18 depicts the generic site amplification spectra for all the site classes in the city. The PGA 

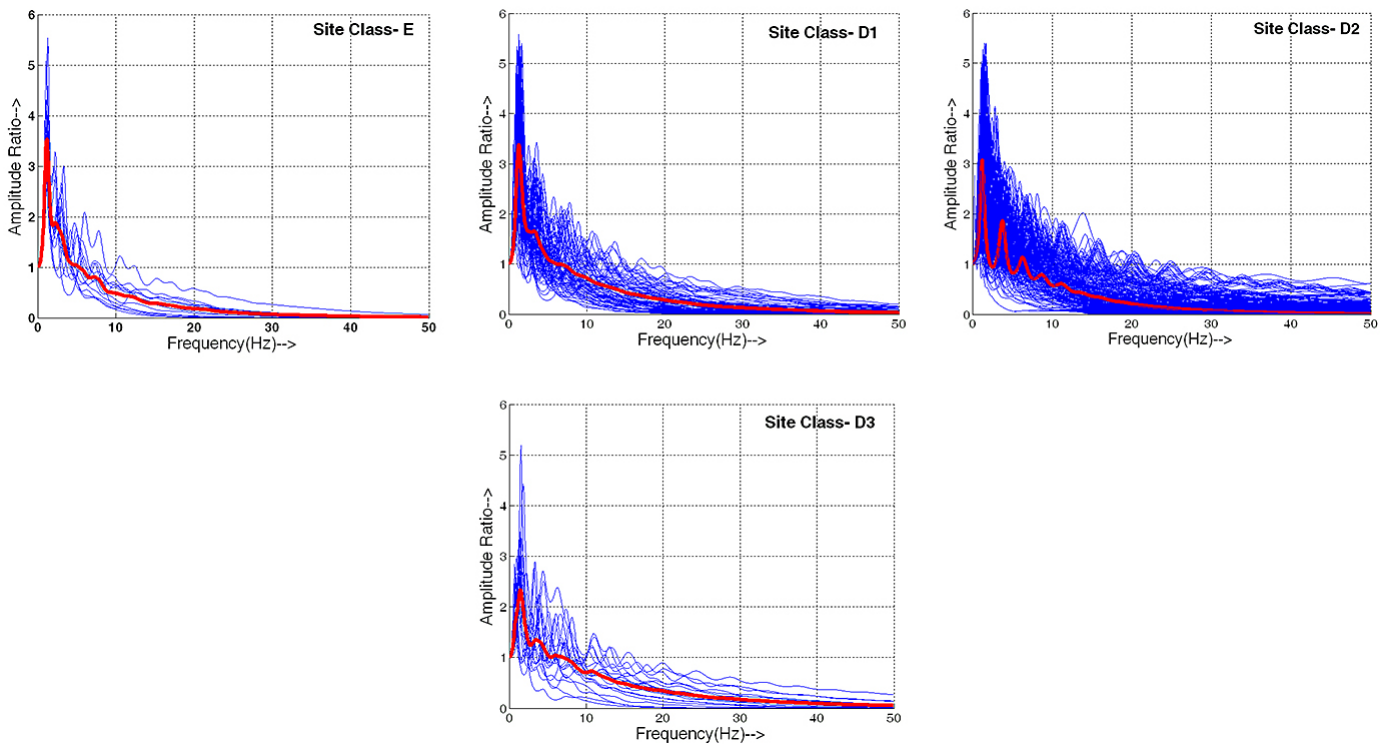

Figure 18. Generic site amplification curves depicting spectral ground motion amplification within a frequency band encompassing the fundamental and higher order modes for all the site classes defined in Fig. 17 (blue curves represent a composite of site amplification curves at all borehole locations in a site class (E, D1, D2, D3), while the red curve represents the average site amplification curve for each site class).

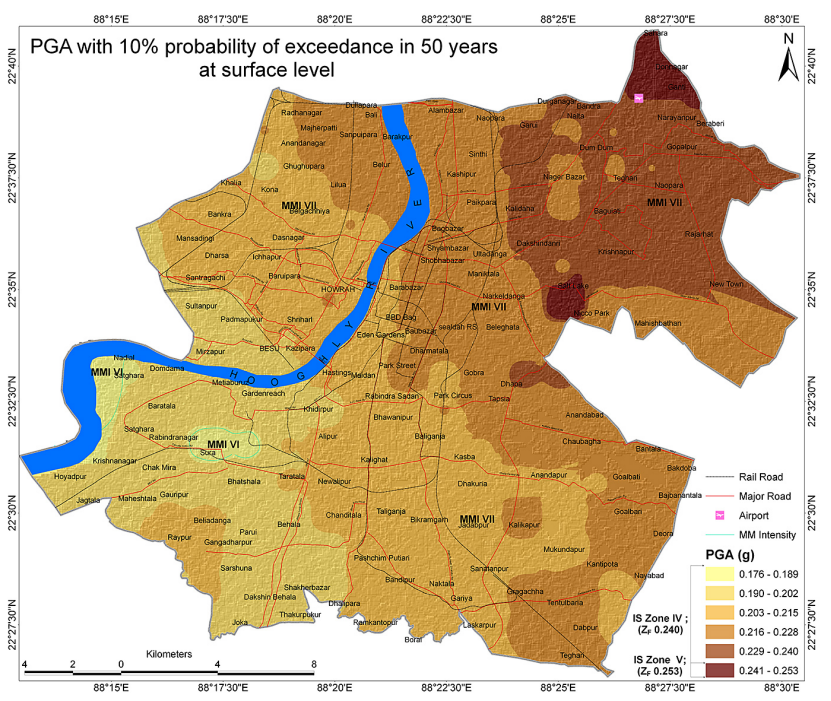

Figure 19. Spatial distribution of PGA in Kolkata with $10 \%$ probability of exceedance in 50 years at surface placing the city in the distinct updated BIS zones IV and V with probable zone factors of 0.240 and 0.253 and MM intensities of VI and VII, respectively.

for $10 \%$ probability of exceedance in 50 years computed at the surface and presented in Fig. 19 exhibits a variation from 0.176 to $0.253 \mathrm{~g}$ with probable zone factors (PGA thresholds for each of these zones) of 0.240 and 0.253 in two updated distinct BIS-compliant zones - IV and V. The probabilistic surface-consistent PGA projects a seismic intensity following Wald et al. (1999) to vary between MM VI and VII in the entire city, where the potential damage distribution varies from light to moderate. The $5 \%$ damped design response spectra generated using PSA at 1.0 and $0.2 \mathrm{~s}$ with $10 \%$ probability of exceedance in 50 years following the International Building Code (IBC, 2009) for selected locations/landmarks in Kolkata at both the bedrock and the surface presented in Fig. 20 exhibit an increase in the design values for updating of the existing building code and imply a probable escalation in the urbanization cost of the city.

\subsection{Ground water table and soil liquefaction assessment}

Ground water table depth is among the major factors affecting the stability of soil. The main water-bearing formation of the region is Quaternary alluvium consisting of sands of various grades interbedded with silt and clay. The high groundwater levels create favorable conditions for the occurrence of liquefaction during an earthquake (Yilmaz and Bagci, 2006). In the present study, water table depths obtained from 350 boreholes calibrated with a post-monsoon piezometer survey are used to generate a water table depth variation map of the city, as shown in Fig. 21 depicting water table level ranging between 0.1 and $7.7 \mathrm{~m}$. Thus the sediment properties in terms of lithology, age of the deposit, grain size, shape and deposit compactness, along with geomorphology, hydrogeological conditions (i.e., groundwater level) and uncompacted artificial fills, constitute favorable conditions for ground motion amplification in the city as well as causing it to be prone to imminent liquefaction hazard (Updike et al., 1988; Yamamuro and Hade, 1999; Youd and Perkins, 1978; Yilmaz and Bagci, 2006). 

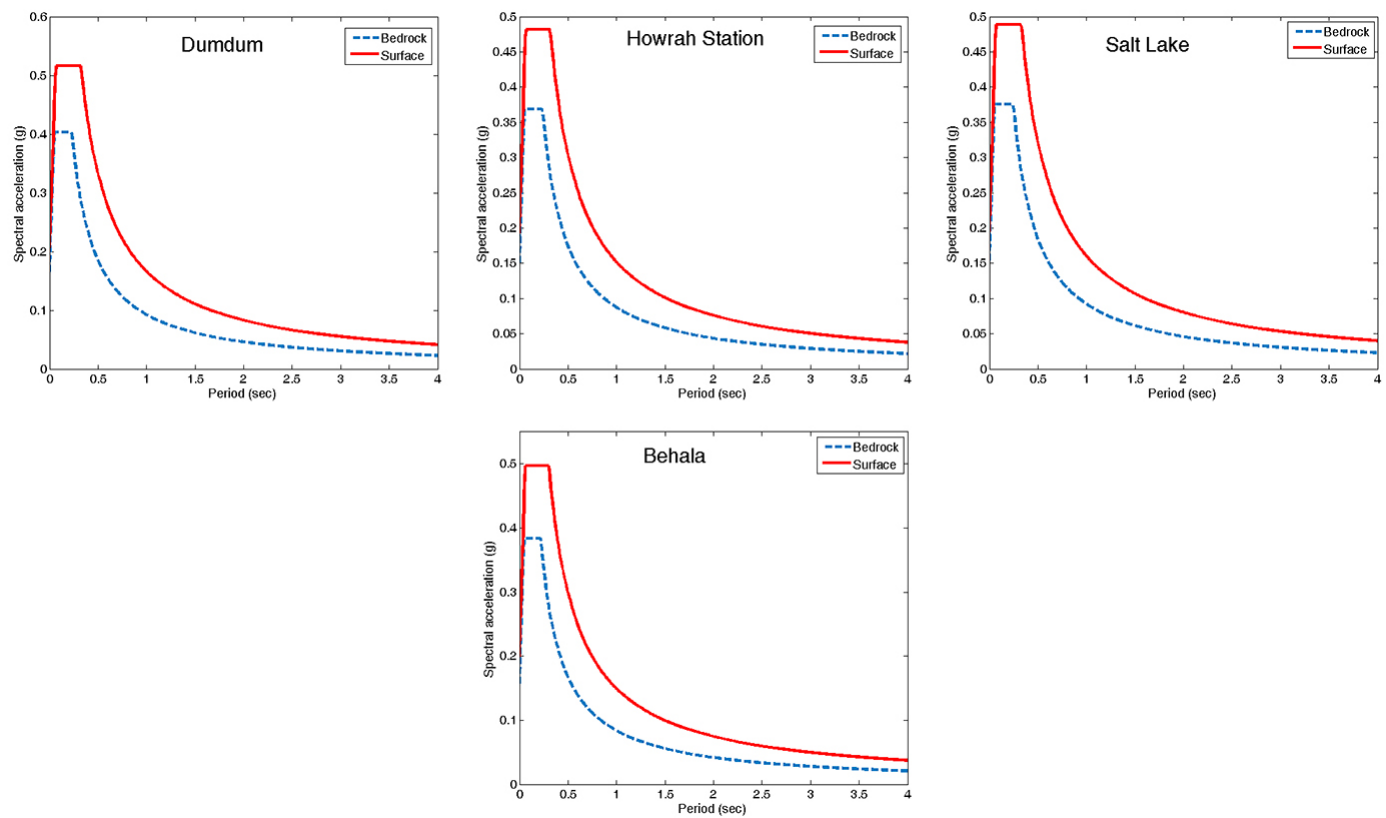

Figure 20. Design response spectra (5\% damped) generated using PSA at 1 and $0.2 \mathrm{~s}$ with $10 \%$ probability of exceedance in 50 years for selected locations/landmarks in Kolkata at both engineering bedrock and surface levels. An increase in the design values due to modification in the building code can be observed, which implies an escalation in the probable cost of urbanization.

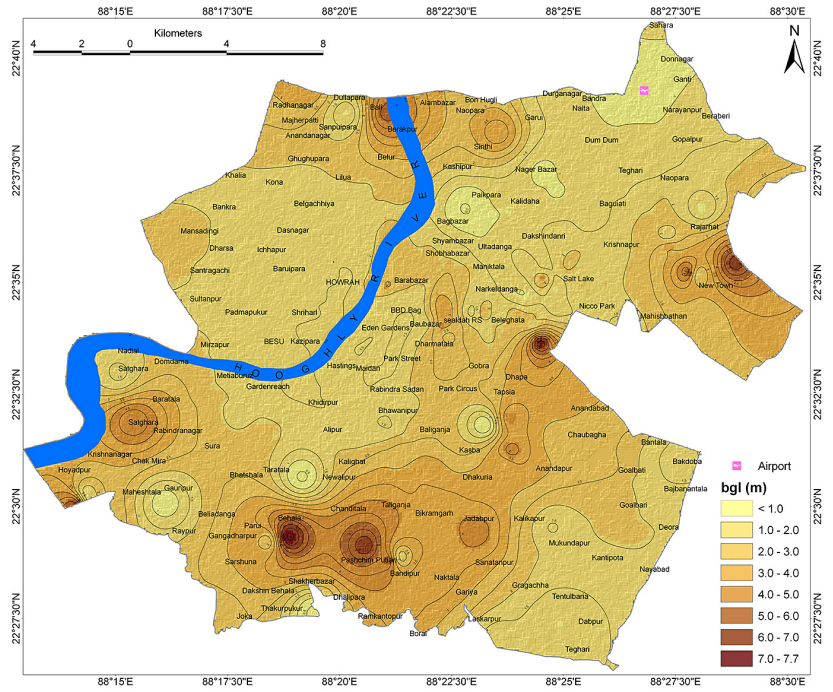

Figure 21. Post-monsoon water table level in Kolkata derived from both the piezometric survey and dug well information.

Soil liquefaction is a secondary phenomenon associated with an earthquake which plays a major role in increasing the seismic risk of a province. It is generally observed in cohesionless saturated soil when, because of dynamic loading and increase in pore water pressure, the shear strength of the soil decreases to zero. The liquefaction potential is convention- ally expressed as the factor of safety (FOS), which indicates the site's ability to resist liquefaction and assumes a value greater or smaller than 1 according to whether the site is considered to be safe or not. The FOS does not give any information about the severity of liquefaction, which can be quantified by the probability of liquefaction $\left(P_{\mathrm{L}}\right)$. Also, in order to consider the hazard of liquefaction for the entire soil column, a liquefaction potential index (LPI) for a depth of up to $20 \mathrm{~m}$ is calculated. A holistic framework for soil liquefaction assessment based on Seed and Idriss (1971), Youd et al. (2001), Idriss and Boulanger (2006) and Iwasaki et al. (1982) formulations, depicted in Fig. 22, is used to generate a deterministic liquefaction scenario (Juang and $\mathrm{Li}, 2007$ ) in the city that corresponds to the surface PGA distribution with $10 \%$ probability of exceedance in 50 years with the moment magnitude for each PGA derived through a de-aggregation process. To generate the liquefaction susceptibility map of the city of Kolkata, an LPI distribution map is prepared in a GIS platform as shown in Fig. 23. The LPI values have been categorized according to Iwasaki et al. (1982) as nonliquefiable (LPI $=0)$, low $(0<$ LPI $<5)$, high $(5<$ LPI $<15)$ and severe (LPI $>15)$. Large patches of zones with severe liquefaction potential have been identified in the northeastern and eastern regions of the city, encompassing Salt Lake, Rajarhat, Newtown and Nicco Park. The Bihar-Nepal earthquake of $M_{\mathrm{w}} 8.1$ caused considerable damage to life and property (GSI, 1939): in the form of cracks in the buildings with subsidence and collapse as reported, presumably due to the effect of soil liquefaction triggered by the intensifying 




Figure 22. A framework for soil liquefaction susceptibility assessment.

ground motion coupled with the shallow ground water table and the thick alluvial-filled Bengal Basin. The reported liquefaction-triggered damage due to the impact of the 1934 Bihar-Nepal earthquake is seen to occur mostly in the zones of high liquefaction susceptibility.

\section{Multicriteria seismic hazard microzonation of Kolkata}

Multicriteria seismic hazard microzonation has been carried out previously in other Indian regions - Guwahati (Nath et al., 2007), the Sikkim Himalaya (Nath, 2004; Pal et al., 2008), Delhi (Mohanty et al., 2007), Bangalore (Anbazhagan et al., 2010) and Chennai (Ganapathy, 2011).The hazard mapping is achieved through use of a multicriteria-based decision support tool formulated by Saaty (1980) referred to as an analytical hierarchal process (AHP). AHP uses hierarchical structures to quantify relative priorities for a given set of elements on a ratio scale, which is based on the discernment of the user. From the judgments between two particular elements, a pairwise comparison matrix is constructed on a scale of integer factors 1-6, indicating an increasing importance of the elements. The ratio between such factors defines the relative importance of one element to another (Anbazhagan et al., 2010). The pairwise comparison matrix that has been prepared is used to derive the individual normalized weights of each element. The weights of each criterion are calculated by summing up all the ratios in the relative matrix column and then dividing each element in the matrix by its column total to generate a normalized pairwise matrix, and then the weighted matrix is generated by dividing the sum of the normalized row by the number of criteria used. The consistency index (CI) is an important feature of the AHP that enables the rating inconsistencies to be determined (Saaty, 2000). The consistency ratio (CR), which is a comparison between the $\mathrm{CI}$ and the random index (RI) obtained using the AHP method, is $<0.1$. Saaty (1980) developed an average RI for different matrix orders. The weights are normalized to 1 and 


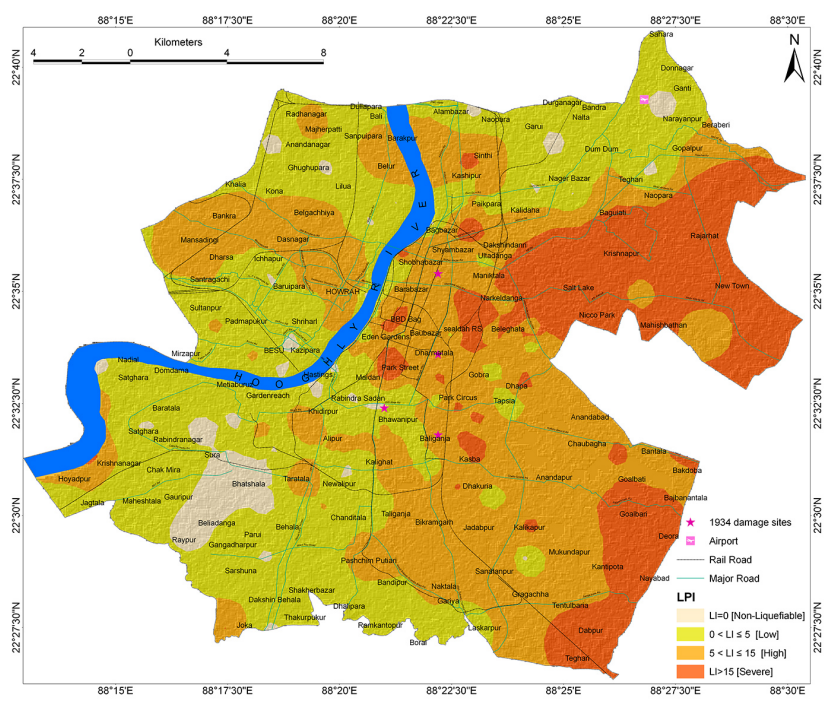

Figure 23. Liquefaction potential index (LPI) distribution in Kolkata. An LPI $>15$ indicates a severe liquefaction hazard condition, an LPI between 5 and 15 indicates a tendency to liquefy, and LPI around 5 depicts a non-liquefiable condition.

can be used in deriving the weighted sums of rating for each region of polygons of the mapped layers. Within each theme, the values vary significantly and are hence reclassified into various ranges or types collectively referred to as a feature of a thematic layer. The associated feature attributes are scored within the theme. The initial integral scoring, $X_{j}$, is normalized to ensure that no layer exerts an influence beyond its determined weight using the following relation (Nath, 2004):

$X_{j}=\frac{R_{j}-R_{\min }}{R_{\max }-R_{\min }}$,

where $R_{j}$ is the row score and $R_{\max }$ and $R_{\min }$ are the maximum and minimum scores of a particular layer.

The hazard themes pertaining to the study region which are materialized as thematic layers on the GIS platform are (i) peak ground acceleration (PGA) at the surface, (ii) the liquefaction potential index (LPI), (iii) NEHRP soil site class (SC), (iv) sediment class (SEC), (v) geomorphology (GM), and (vi) ground water table (GWT). Each thematic layer has been georectified on a Universal Transverse Mercator projection system. The corresponding weights, the ranks of each thematic layer, and the theme attribute score thereof are assigned values according to the apparent contribution of the layers to the overall seismic hazard. For example, in the geomorphology theme, with regard to severity to liquefaction, we have assigned a ranking of "high" to swampy land, water bodies and river channels and "low" to paleochannel (Youd and Perkins, 1978; Ganapathy and Rajawat, 2012). In the sediment class, considering the effect on the FOS, higher rank is assigned to sand, clayey sand and silty sand, whereas

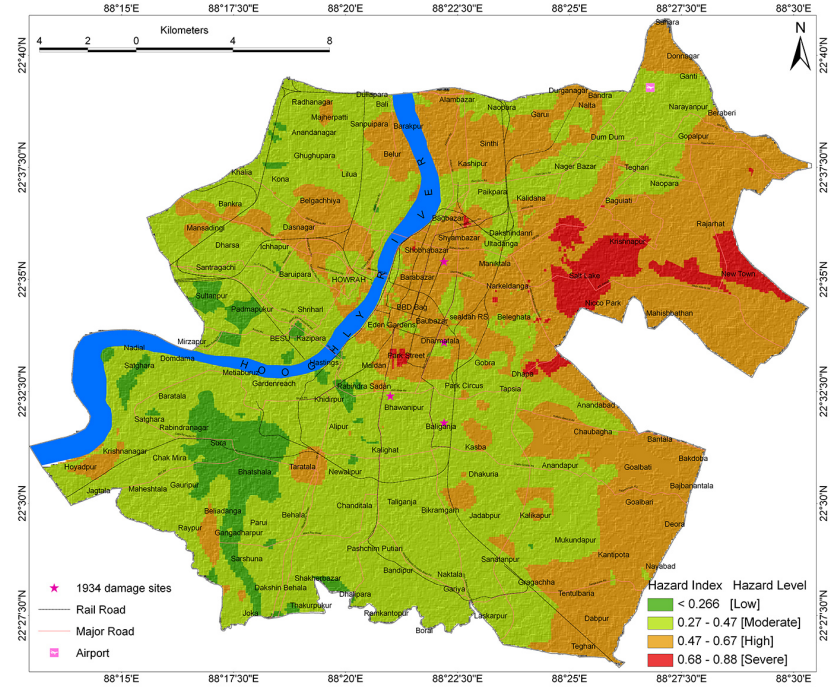

Figure 24. Probabilistic seismic hazard microzonation map of Kolkata. Four broad divisions have been identified with the hazard index (HI), defined as $0.68<\mathrm{HI} \leq 0.88$, indicating severe hazard conditions, in the areas of Salt Lake and New Town; $0.47<\mathrm{HI} \leq 0.68$, indicating high hazard conditions, mostly in the areas of Rajarhat and Mahishbathan of the expanding city; $0.27<\mathrm{HI} \leq 0.47$, indicating moderate hazard conditions, in the most part of south and west Kolkata; and $\mathrm{HI}<0.27$, indicating a completely hazard-free regime. The damage distribution due to the 1934 Bihar-Nepal earthquake of $M_{\mathrm{W}} 8.1$ is reported (GSI, 1939) to have induced an MM intensity order of VI-VII in Kolkata, mostly identified in the moderate to high hazard zones (marked with a star). The detailed seismological and geohazard attributions for each division are presented in Table 10.

the lowest rank is assigned to clay (Youd and Perkins, 1978; Yamamuro and Hade, 1999). Table 8 presents the pairwise comparison matrix for the respective themes and their normalized weights. The normalized ranks assigned to the features of each theme are listed in Table 9. All the georeferenced thematic layers are integrated step by step using the aggregation method in GIS to generate a seismic hazard microzonation map (SHM):

$$
\begin{aligned}
& \mathrm{SHM}=\left[\mathrm{PGA}_{\mathrm{W}} \mathrm{PGA}_{\mathrm{r}}+\mathrm{LPI}_{\mathrm{W}} \mathrm{LPI}_{\mathrm{r}}+\mathrm{SC}_{\mathrm{W}} \mathrm{SC}_{\mathrm{r}}\right. \\
& \left.+\mathrm{SEC}_{\mathrm{w}} \mathrm{SEC}_{\mathrm{r}}+\mathrm{GM}_{\mathrm{w}} \mathrm{GM}_{\mathrm{r}}+\mathrm{GWT}_{\mathrm{w}} \mathrm{GWT}_{\mathrm{r}}\right] / \sum w,
\end{aligned}
$$

where " $\mathrm{w}$ " represents the normalized weight of a theme and " $\mathrm{r}$ " is the normalized rank of a feature in the theme. Thereafter, a $3 \times 3$ "majority filter" is applied to the SHM as a post-classification filter to reduce the high-frequency variation. SHM is a dimensionless quantity that helps in indexing the seismic hazard and hence the microzonation of a region into a qualitative scheme such as "low", "moderate", "high" and "severe". The probabilistic seismic hazard microzonation map of Kolkata shown in Fig. 24 depicts four broad divisions with a hazard index (HI) defined as $0.68<\mathrm{HI} \leq 0.88$ for "severe" hazard conditions, in Salt Lake and New Town 
Table 8. Pair-wise comparison matrix of themes used for seismic hazard microzonation and their normalized weights.

\begin{tabular}{lccccccc}
\hline Themes & PGA & LPI & SC & SEC & GM & GWT & Weight \\
\hline Peak ground acceleration (PGA) & 1 & $6 / 5$ & $6 / 4$ & $6 / 3$ & $6 / 2$ & $6 / 1$ & 0.2864 \\
Liquefaction potential index (LPI) & $5 / 6$ & 1 & $5 / 4$ & $5 / 3$ & $5 / 2$ & $5 / 1$ & 0.2381 \\
Site class (SC) & $4 / 6$ & $4 / 5$ & 1 & $4 / 3$ & $4 / 2$ & $4 / 1$ & 0.1905 \\
Sediment class (SEC) & $3 / 6$ & $3 / 5$ & $3 / 4$ & 1 & $3 / 2$ & $3 / 1$ & 0.1429 \\
Geomorphology (GM) & $2 / 6$ & $2 / 5$ & $2 / 4$ & $2 / 3$ & 1 & $2 / / 1$ & 0.0952 \\
Ground water table (GWT) & $1 / 6$ & $1 / 5$ & $1 / 4$ & $1 / 3$ & $1 / 2$ & $1 / 1$ & 0.0476 \\
\hline
\end{tabular}

Table 9. Normalized weights and ranks assigned to respective themes and the features thereof for thematic integration.

\begin{tabular}{|c|c|c|c|c|}
\hline Theme & Weight & Attributes & Rating & $\begin{array}{l}\text { Normalized } \\
\quad \text { rating }\end{array}$ \\
\hline \multirow[t]{6}{*}{ Peak ground motion (PGA) } & \multirow[t]{6}{*}{0.2864} & $0.176-0.189(g)$ & 1 & 0.00 \\
\hline & & $0.190-0.202$ & 2 & 0.20 \\
\hline & & $0.202-0.215$ & 3 & 0.40 \\
\hline & & $0.216-0.228$ & 4 & 0.60 \\
\hline & & $0.229-0.240$ & 5 & 0.80 \\
\hline & & $0.241-0.253$ & 6 & 1.00 \\
\hline \multirow{4}{*}{$\begin{array}{l}\text { Liquefaction potential index } \\
\text { (LPI) }\end{array}$} & \multirow[t]{4}{*}{0.2381} & 0 (non-liquefiable) & 1 & 0.00 \\
\hline & & $0.1-5.0$ (low) & 2 & 0.33 \\
\hline & & 5.1-15.0 (high) & 3 & 0.66 \\
\hline & & $>15.0$ (severe) & 4 & 1.00 \\
\hline \multirow[t]{4}{*}{ Site class (SC) } & \multirow[t]{4}{*}{0.1905} & D3 $\left(V_{\mathrm{s}}^{30} 300-358 \mathrm{~m} \mathrm{~s}^{-1}\right)$ & 1 & 0.00 \\
\hline & & $\mathrm{D} 2\left(V_{\mathrm{s}}^{30} 240-300 \mathrm{~m} \mathrm{~s}^{-1}\right)$ & 2 & 0.33 \\
\hline & & $\mathrm{D} 1\left(V_{\mathrm{s}}^{30} 180-240 \mathrm{~m} \mathrm{~s}^{-1}\right)$ & 3 & 0.66 \\
\hline & & $\mathrm{E}\left(V_{\mathrm{s}}^{30} 119-180 \mathrm{~m} \mathrm{~s}^{-1}\right)$ & 4 & 1.00 \\
\hline \multirow[t]{5}{*}{ Sediment class (SEC) } & \multirow[t]{5}{*}{0.1429} & Clay & 1 & 0.00 \\
\hline & & Gravelly sediment & 2 & 0.25 \\
\hline & & Silty clay, silt, clayey silt & 3 & 0.50 \\
\hline & & Sandy clay, sandy-silty clay, sandy silt & 4 & 0.75 \\
\hline & & Sand, clayey sand, silty sand & 5 & 1.00 \\
\hline \multirow[t]{5}{*}{ Geomorphology (GM) } & \multirow[t]{5}{*}{0.0952} & Paleochannel & 1 & 0.00 \\
\hline & & Older Levee & 2 & 0.25 \\
\hline & & Interdistributary marsh & 3 & 0.50 \\
\hline & & Deltaic plains, younger levee & 4 & 0.75 \\
\hline & & Water bodies, canal, river, swampy land & 5 & 1.00 \\
\hline \multirow[t]{8}{*}{ Ground water table (GWT) } & \multirow[t]{8}{*}{0.0476} & $<1.0$ (b.g.1. in $\mathrm{m})$ & 8 & 1.00 \\
\hline & & $1.0-2.0$ & 7 & 0.86 \\
\hline & & $2.1-3.0$ & 6 & 0.71 \\
\hline & & $3.1-4.0$ & 5 & 0.52 \\
\hline & & $4.1-5.0$ & 4 & 0.42 \\
\hline & & $5.1-6.0$ & 3 & 0.29 \\
\hline & & $6.1-7.0$ & 2 & 0.14 \\
\hline & & $7.1-7.7$ & 1 & 0.00 \\
\hline
\end{tabular}


Table 10. Microzonation hazard level with corresponding geophysical and geotechnical attributes at selected locations in Kolkata.

\begin{tabular}{llcclccc}
\hline Location & Hazard level & PGA $(g)$ & $P_{\mathrm{F}}$ & LPI & $\mathrm{SC} / V_{\mathrm{S}}^{30}$ & I $_{\mathrm{MM}}$ & $S_{\mathrm{A}}$ \\
\hline Behala & Moderate & 0.196 & 1.41 & 3.30 (low) & $\mathrm{D} 2 / 272.9$ & VII & 3.36 \\
Rajdanga & Moderate & 0.214 & 1.47 & 12.07 (high) & $\mathrm{D} 2 / 258.0$ & VII & 3.68 \\
Shyambazar & High & 0.217 & 2.38 & 13.50 (high) & $\mathrm{D} 2 / 258.0$ & VII & 3.09 \\
Dum Dum & Moderate & 0.228 & 1.38 & 4.71 (low) & $\mathrm{D} 2 / 269.2$ & VII & 3.42 \\
Barahanagar & High & 0.223 & 1.54 & 11.45 (high) & $\mathrm{D} 2 / 274.4$ & VII & 3.36 \\
Bali & Moderate & 0.221 & 1.51 & 4.85 (low) & D2/274.4 & VII & 3.47 \\
Kona & Moderate & 0.213 & 1.44 & 9.39 (high) & D2/280.1 & VII & 3.86 \\
Maheshtala & Moderate & 0.196 & 1.38 & 3.60 (low) & D2/258.0 & VII & 3.42 \\
Alipur & Moderate & 0.204 & 1.73 & 10.11 (high) & D2/253.4 & VII & 3.73 \\
Metiaburuz & Moderate & 0.195 & 1.44 & 4.60 (low) & D2/258.0 & VII & 3.63 \\
Sura & Low & 0.178 & 1.63 & 0 (non-liquefiable) & D2/264.5 & VI & 3.64 \\
Jadabpur & Moderate & 0.210 & 1.51 & 13.50 (high) & D2/258.0 & VII & 3.90 \\
Kalighat & Moderate & 0.208 & 1.35 & 4.16 (low) & D2/258.0 & VII & 3.47 \\
Deora & High & 0.219 & 1.44 & 21.16 (severe) & D1/215.4 & VII & 2.51 \\
Dhakuria & Moderate & 0.213 & 0.95 & 14.35 (high) & D2/258.0 & VII & 3.29 \\
Thakurpukur & Moderate & 0.199 & 1.53 & 3.76 (low) & D2/267.0 & VII & 3.85 \\
Satghara & Moderate & 0.179 & 1.41 & 4.03 (low) & D2/248.6 & VI & 3.09 \\
Belur & High & 0.219 & 1.97 & 11.76 (high) & D2/280.1 & VI & 3.29 \\
Bakdoba & High & 0.219 & 1.44 & 12.67 (high) & D2/258.0 & VII & 2.86 \\
Paikpara & Moderate & 0.223 & 1.20 & 12.07 (high) & D2/270.3 & VII & 3.23 \\
Park Street & Severe & 0.216 & 1.35 & 24.36 (severe) & E/174.3 & VII & 3.80 \\
Salt Lake & Severe & 0.236 & 1.17 & 28.09 (severe) & E/163.1 & VII & 4.22 \\
New Town & Severe & 0.228 & 1.20 & 26.50 (severe) & D2/267.3 & VII & 3.73 \\
Rajarhat & High & 0.230 & 0.95 & 34.28 (severe) & D2/244.6 & VII & 3.23 \\
\hline
\end{tabular}

$P_{\mathrm{F}}$ : predominant frequency $(\mathrm{Hz}) ; \mathrm{LPI}$ : liquefaction potential index; $\mathrm{SC} / V_{\mathrm{S}}^{30}: \mathrm{NEHRP}$ site class/effective shear wave velocity $\left(\mathrm{m} \mathrm{s}^{-1}\right)$ of $\sim 30 \mathrm{~m}$ soil column; $I_{\mathrm{MM}}$ : predicted modified Mercalli intensity (Richter, 1958); $S_{\mathrm{A}}$ : site amplification.

areas; $0.47<\mathrm{HI} \leq 0.68$ for "high" hazard conditions, mostly in the areas of Rajarhat and Mahishbathan of the expanding city; and $0.27<\mathrm{HI} \leq 0.47$ for "moderate" hazard conditions, in most parts of south and west Kolkata. The damage distributions due to the great 1934 Bihar-Nepal earthquake are mostly identified in the moderate to high hazard zone (marked with a star). The detailed seismological and geohazard attributions for each division are presented in Table 10.

\section{Conclusions}

Seismic hazard microzonation has emerged as an important issue in high-risk urban centers across the globe and is considered an integral part of earthquake-related disaster mitigation practices. A new perspective of multicriteria holistic seismic hazard assessment has been presented here for Kolkata based on an enriched homogeneous earthquake catalog; an upgraded tectonic database; seismotectonic implications; and geological, geotechnical and geophysical databases, all judiciously integrated in a fuzzy protocol using the sophisticated analytical technology coupled with a geographical information system. It has provided an enhanced seismic scenario in microscale $(1: 25000)$ with the development of a set of next-generation attenuation mod- els, NEHRP site characterization with associated generic site response spectra, liquefaction scenarios, and surfaceconsistent PGA distribution with upgraded $5 \%$ damped design response spectra depicting an increase in the design values for an appropriate modification in the building code of the city of Kolkata.

Acknowledgements. This work has been supported by the Seismology Division of the Ministry of Earth Sciences, Government of India, vide sanction order no. MoES/P.O.(Seismo)/1(60)/2009. The Department of Science \& Technology; the Government of West Bengal; Jadavpur University; the Indian Institute of Engineering Science \& Technology, Shibpur; and the Center for Ground Water Studies, Kolkata, all actively participated at various stages of the project. The support received for the smooth execution of the project from the Department of Disaster Management and Civil Defence, Government of West Bengal, especially from Shri Javed Ahmed Khan, the minister-in-charge of the department, is thankfully acknowledged. We greatly appreciate the tremendous support received from David Keefer, the NHESS handling editor, for this manuscript during its long review process. The three anonymous reviewers critically examined the manuscript and its subsequent revisions, suggesting several valuable changes that greatly helped in bringing the manuscript to its present state with enhanced quality and scientific exposition. 
Edited by: D. Keefer

Reviewed by: three anonymous referees

\section{References}

Aki, K.: Maximum likelihood estimate of $b$ in the formula $\log N=a-b M$ and its confidence limits, Bull. Earthq, Res. Ins., 43, 237-239, 1965.

Alam, M., Alam, M. M., Curray, J. R., Chowdhury, M. L. R., and Gani, M. R.: An overview of sedimentary geology of the Bengal basin in relation to the regional framework and basin-fill history, Sediment. Geol., 155, 179-208, 2003.

Allen, T. I., Gibson, G., Brown, A., and Cull, J. P.: Depth variation of seismic source scaling relations: Implications for earthquake hazard in southeastern Australia, Tectonophysics, 390, 524, 2004.

Anbazhagan, P., Thingbaijam, K. K. S., Nath, S. K., Narendara Kumar, J. N., and Sitharam, T. G.: Multi-criteria seismic hazard evaluation for Bangalore city, India, J. Asian Earth Sci., 38, 186198, 2010 .

Atkinson, G. M. and Boore, D. M.: Earthquake ground-motion predictions for eastern North America, Bull. Seismol. Soc. Am., 96, 2181-2205, 2006.

Azzaro, R., Ferreli, L., Michetti, A. M., Serva, L., and Vittori, E.: Environmental Hazard of Capable Faults: The Case of the Pernicana Fault, Mt. Etna, Sicily, Nat. Hazards, 17, 147-162, 1998.

Bender, B.: Maximum likelihood estimation of b-values for magnitude grouped data, Bull. Seismol. Soc. Am, 73, 831-851, 1983.

Besana, G. M. and Ando, M.: The central Philippine Fault Zone: Location of great earthquakes, slow events, and creep activity, Earth Planets Space, 57, 987-994, 2005.

Bilham, R. and England, P.: Plateau 'pop up' in the great 1897 Assam earthquake, Nature, 410, 806-809, 2001.

BIS: IS 1893-2002 (Part 1): Indian Standard Criteria for Earthquake Resistant Design of Structures, Part 1 - General Provisions and Buildings, Bureau of Indian Standards, New Delhi, 2002.

Bommer, J. J. and Abrahamson, N. A.: Why Do Modern Probabilistic Seismic-Hazard Analysis Often Lead to Increase Hazard Estimates?, Bull. Seismol. Soc. Am., 96, 1967-1977, 2006.

Cáceres, D., Monterroso, D., and Tavakoli, B.: Crustal deformation in northern Central America, Tectonophysics, 404, 119-131, 2005.

Campbell, K. W. and Bozorgnia, Y.: Updated near-source groundmotion (attenuation) relations for the horizontal and vertical components of peak ground acceleration and acceleration response spectra, Bull. Seismol. Soc. Am., 93, 314-331, 2003.

Campbell, K. W. and Bozorgnia, Y.: NGA ground motion model for the geometric mean horizontal component of PGA, PGV, PGD and $5 \%$ damped linear elastic response spectra for periods ranging from 0.01 to $10 \mathrm{~s}$, Earthq. Spectra, 24, 139-171, 2008.

Chandra, U.: Earthquakes of Peninsular India A seismotectonic study, Bull. Seismol. Soc. Am., 67, 1387-1413, 1977.

Christova, C.: Seismicity depth pattern, seismic energy and b value depth variation in the Hellenic Wadati-Benioff zone, Phys. Earth Planet. Int., 72, 38-48, 1992.

Cornell, C. A.: Engineering Seismic Risk Analysis, Bull. Seismol. Soc. Am., 58, 1583-1606, 1968.
Cornell, C. A. and Vanmarcke, E. H.: The major influence on seismic risk, The 4th world conference on earthquake engineering, Santiago, Chile, 69-93, 1969.

Das, S. and Henry, C.: Spatial relation between main earthquake slip and its aftershock distribution, Rev. Geophys., 41, 1013, doi:10.1029/2002RG000119, 2003.

Dasgupta, S., Sural, B., Harendranath, L., Mazumadar, K., Sanyal, S., Roy, A., Das, L. K., Misra, P. S., and Gupta, H.: Seismotectonic Atlas of India and its Environs, Geological Survey of India, Calcutta, India, 2000.

Dietz, L. D. and Ellsworth, W. L.: The October 17, 1989, Loma Prieta, California, earthquake and its aftershocks: geometry of the sequence from high-resolution locations, Geophys. Res. Lett., 17, 1417-1420, 1990.

Engdahl, E. R., Van Der Hilst, R., and Bulland, R.: Global teleseismic earthquake relocation with improved travel times and procedures for depth determination, Bull. Seismol. Soc. Am., 88, 722-743, 1998.

Esteva, L.: Seismic Risk and Seismic Design Decisions, in: Seismic Design for Nuclear Power Plants, edited by: Hansen, R. J., Massachusetts Institute of Technology Press, Cambridge, MA, USA, 1970.

Frankel, A.: Mapping Seismic Hazard in the central and eastern United States, Seismol. Res. Let., 66, 8-21, 1995.

Ganapathy, G. P.: First level seismic microzonation map of Chennai city - a GIS approach, Nat. Hazards Earth Syst. Sci., 11, 549559, doi:10.5194/nhess-11-549-2011, 2011.

Ganapathy, G. P. and Rajawat, A. S.: Evaluation of liquefaction potential hazard of Chennai city, India: using geological and geomorphological characteristics, Nat. Hazards, 64, 1717-1729, 2012.

Grünthal, G. and Wahlström, R.: New generation of probabilistic seismic hazard assessment for the area Cologne/Aachen considering the uncertainties of the input data, Nat. Hazards, 38, 159176, 2006.

GSB: Geological map of Bangladesh, Geological Survey of Bangladesh, Dhaka, Bangladesh, 1990.

GSI: The Bihar-Nepal Earthquake of 1934, Mem. 73, Geol. Surv. India, Calcutta, 391 pp., 1939.

Gutenberg, B. and Richter, C. F.: Frequency of earthquakes in California, Bull. Seismol. Soc. Am., 34, 185-188, 1944.

Hashash, Y. M. A.: DEEPSOIL V 3.7, Tutorial and User Manual, University of Illinois at Urbana-Champaign, Urbana, Illinois, 2009.

Herak, M.: ModelHVSR - A Matlab tool to model horizontal-tovertical spectral ratio of ambient noise, Comput. Geosci., 34, 1514-1526, 2008.

IBC: International Building Code, International Code Council, Inc., Country Club Hills, Illinois, 2009.

Idriss, I. M. and Boulanger, R. W.: Semi-empirical procedures for evaluating liquefaction potential during earthquakes, Soil. Dyn. Earthq. Eng., 26, 115-130, 2006.

Iwasaki, T., Tokida, K., Tatsuoka, F., Watanabe, S., Yasuda, S., and Sato, H.: Microzonation for soil liquefaction potential using simplified methods, In: Proceedings of 3rd international conference on microzonation, Seattle, 3, 1319-1330, 1982.

Jaiswal, K. and Sinha, R.: Webportal on earthquake disaster awareness in India, http://www.earthquakeinfo.org/Catalog_Data.htm, 2004. 
Juang, C. H. and Li, D. K.: Assessment of liquefaction hazards in Charleston Quadrangle, South Carolina, Eng. Geol., 92, 59-72, 2007.

Kafka, A. L.: Does seismicity delineate zones where future large earthquakes are likely to occur in intraplate environments?, Geol. Soc. Am. Spec. Pap., 425, 35-48, 2007.

Kagan, Y. Y. and Jackson, D. D.: Long-term probabilistic forecasting of earthquakes, J. Geophys. Res., 99, 13685-13700, 1994.

Kalkan, E., Gülkan, P., Yilmaz, N., and Çelebi, M.: Reassessment of probabilistic seismic hazard in the Marmara region, Bull. Seismol. Soc. Am., 99, 2127-2146, 2009.

Kanamori, H. and Anderson, D. L.: Theoretical basis of some empirical relations in seismology, Bull. Seismol. Soc. Am., 65, 1073-1096, 1975.

Kayabalia, K. and Akin, M.: Seismic hazard map of Turkey using the deterministic approach, Eng. Geol., 69, 127-137, 2003.

Kijko, A.: Estimation of the Maximum Earthquake Magnitude, Pure Appl. Geophys., 161, 1655-1681, 2004.

Marin, S., Avouac, J. P., Nicolas, M., and Schlupp, A.: A probabilistic approach to seismic hazard in metropolitan France, Bull. Seismol. Soc. Am., 94, 2137-2163, 2004.

Mark, R. K.: Application of linear statistical model of earthquake magnitude versus fault length in estimating maximum expectable earthquakes, Geology, 5, 464-466, 1977.

Martin, S. and Szeliga, W.: A catalog of felt intensity data for 589 earthquakes in India, 636-2008, Bull. Seismol. Soc. Am., 100, 562-569, 2010.

McGuire, R. K.: FORTRAN Computer Program for Seismic Risk Analysis, US Geological Survey, available at: http://pubs.er.usgs. gov/publication/ofr7667, 76-67, 1976.

Middlemiss, C. S.: Two Calcutta Earthquakes of 1906, Rec. Geol. Surv. Ind., 36, 214-232, 1908.

Mohanty, W. K., Walling, M. Y., Nath, S. K., and Pal, I.: First Order Seismic Microzonation of Delhi, India Using Geographic Information System (GIS), Nat. Hazards, 40, 245-260, 2007.

Motazedian, D. and Atkinson, G. M.: Stochastic finite-fault modeling based on a dynamic corner frequency, Bull. Seismol. Soc. Am., 95, 995-1010, 2005.

Nath, S. K.: Seismic Hazard Mapping and Microzonation in the Sikkim Himalaya through GIS Integration of Site Effects and Strong Ground Motion Attributes, Nat. Hazards, 31, 319-342, 2004.

Nath, S. K. and Thingbaijam, K. K. S.: Assessment of seismic site conditions: a case study from Guwahati City, Northeast India, Pure Appl. Geophys., 168, 1645-1668, 2011a.

Nath, S. K. and Thingbaijam, K. K. S.: Probabilistic seismic hazard assessment of India, Seismol. Res. Lett., 83, 135-149, 2012.

Nath, S. K. and Thingbaijam, K. K. S.: Peak ground motion predictions in India: an appraisal for rock sites, J. Seismol., 15, 295315, 2011 b.

Nath, S. K., Thingbaijam, K. K. S., Raj, A., Shukla, K., Pal, I., Nandy, D. R., Vadav, M. K., Bansal, B. K., Dasgupta, S., Majumdar, K., Kayal, J. R., Shukla, A. K., Deb, S. K., Pathak, J., Hazarika, P. J., and Pal, D. K.: Seismic Microzonation of Guwahati City, International workshop on Earthquake Hazard and Mitigation, Guwahati, India, 2007.
Nath, S. K., Thingbaijam, K. K. S., Vyas, J. C., Sengupta, P., and Dev, S. M. S. P.: Macroseismic-driven site effects in the southern territory of West Bengal, India, Seismol. Res. Lett., 81, 480-487, 2010.

Nath, S. K., Thingbaijam, K. K. S., Maiti, S. K., and Nayak, A.: Ground-motion predictions in Shillong region, northeast India, J. Seismol., 16, 475-488, 2012.

O’Malley, J.: U.S. Geological Survey ArcMap Sediment Classification Tool: Installation and User Guide, USGS, Open-File Report 2007-1186, US Geological Survey, Reston, Virginia, 2007.

Page, R.: Afetrshocks and microaftershocks of the great Alaska earthquake of 1964, Bull. Seismol. Soc. Am., 58, 1131-1168, 1968.

Pal, I., Nath, S. K., Shukla, K., Pal, D. K., Raj, A., Thingbaijam, K. K. S., and Bansal, B. K.: Earthquake Hazard Zonation of Sikkim Himalaya Using a GIS Platform, Nat. Hazards, 45, 333377, 2008.

Parsons, T.: Persistent earthquake clusters and gaps from slip on irregular faults, Nat. Geosci., 1, 59-63, 2008.

Petersen, M. D., Frankel, A. D., Harmsen, S. C., Mueller, C. S., Haller, K. M., Wheeler, R. L., Wesson, R. L., Zeng, Y., Boyd, O. S., Perkins, D. M., Luco, N., Field, E. H., Wills, C. J., and Rukstales, K. S.: Documentation for the 2008 Update of the United States National Seismic Hazard Maps, US Geological Survey Open-File Report 2008-1128, US Geological Survey, Reston, Virginia, Open-File Report 2008-1128, available at: http://pubs.usgs.gov/of/2008/1128/, 2008.

Prozorov, A. G. and Dziewonski, A. M.: A method of studying variations in the clustering property of earthquakes: application to the analysis of global seismicity, J. Geophys. Res., 87, 2829-2839, 1982.

Raghukanth, S. T. G. and Iyengar, R. N.: Estimation of seismic spectral acceleration in Peninsular India, J. Earth Syst. Sci., 116, 199-214, 2007.

Raj, A., Nath, S. K., and Thingbaijam, K. K. S.: A note on recent earthquakes in the Bengal basin, Current Sci., 95, 127-129, 2008.

Reicherter, K., Michetti, A. M., and Silva, P. G.: Palaeoseismology: Historical and Prehistorical Records of Earthquake Ground Effects for Seismic Hazard Assessment, Geol. Soc. Lond. Spec. Publ., 316, 1-10, 2009.

Richter, C. F.: Elementary Seismology, W. H. Freeman and Co., San Francisco, 135-149, 1958.

Roy, P. K., Banerjee, G., Mazumdar, A., Kar, A., Majumder, A., and Roy, M. B.: A Study to ascertain the Optimum Yield from Groundwater Source in the Eastern Part of Kolkata Municipal Corporation Area in West Bengal, India, Eur. J. Sustain. Develop., 1, 97-112, 2012.

Saaty, T. L.: The Analytic Hierarchy Process, McGraw-Hill International, New York, USA, 1980.

Saaty, T. L.: Models, Methods, Concepts and Application of the Analytical Hierarchy Process, Kluwer Academic Publishers, Boston, 2000.

Saragoni, G. R. and Hart, G. C.: Simulation of Artificial Earthquakes, Earthq. Eng. Struct. Dynam., 2, 249-268, 1974.

Schorlemmer, D., Neri, G., Wiemer, S., and Mostaccio, A.: Stability and significance tests for b-value anomalies: Example from the Tyrrhenian Sea, Geophys. Res. Lett., 30, 1835, doi:10.1029/2003GL017335, 2003. 
Schorlemmer, D., Wiemer, S., and Wyss, M.: Variations in earthquake size distribution across different stress regimes, Nature, 437, 539-542, 2005.

Seed, H. B. and Idriss, I. M.: Simplified Procedure for Evaluating Soil Liquefaction Potential, J. Soil Mech. Found. Div.-ASCE, 97, 1249-1273, 1971.

Seyrek, E. and Tosun, H.: Deterministic approach to the seismic hazard of dam sites in Kizilirmak basin, Turkey, Nat. Hazards, 59, 787-800, 2011.

Sharma, M. L., Douglas, J., Bungum, H., and Kotadia, J.: GroundMotion Prediction Equations Based on Data from the Himalayan and Zagros Regions, J. Earthq. Eng., 13, 1191-1210, 2009.

Shepard, F. P.: Nomenclature based on sand-silt-clay ratios, J. Sediment. Petrol., 24, 151-158, 1954.

Shukla, J. and Choudhury, D.: Estimation of seismic ground motions using deterministic approach for major cities of Gujarat, Nat. Hazards Earth Syst. Sci., 12, 2019-2037, doi:10.5194/nhess-12-2019-2012, 2012.

Silva, P. G., Rodríguez Pascua, M. A., Pérez-López, R., Bardaji, T., Lario, J., Alfaro, P., Martínez-Díaz, J. J., Reicherter, K., Giménez García, J., Giner, J., J. Azañón, M. J., Goy, L., and Zazo, C.: Catalogacion de losefectos geologicos y ambientales de los terremotos en Espana en la Escala ESI 2007 y su aplicacion a losestudions paleosismologicos, Geotemas, 6, 1063-1066, 2008.

Singh, D. D. and Gupta H. K.: Source dynamics of two great earthquakes of the Indian Subcontinent: the Bihar-Nepal earthquake of January 15, 1934 and the Quetta earthquake of May 30, 1935, Bull. Seismol. Soc. Am., 70, 757-773, 1980.

Slemmons, D. B. and McKinney, R.: Definition of 'active fault', Miscellaneous Paper S-77-8, US Army Engineer Waterways Experiment Station, Soils and Pavements Laboratory, Vicksburg, Missouri, 23 pp., 1977.

Stirling, M., McVerry, G. H., and Berryman, K. R.: A new seismic hazard model for New Zealand, Bull. Seismol. Soc. Am., 92, 1878-1903, 2002.

Suckale, J. and Grünthal, G.: Probabilistic seismic hazard model for Vanuatu, Bull. Seismol. Soc. Am., 99, 2108-2126, 2009.

Toro, G. R.: Modification of the Toro et al. (1997) attenuation equations for large magnitudes and short distances, Risk Eng. Inc., available at: http://www.riskeng.com/downloads/ attenuationequations, 2002.

Tsapanos, T. M.: The depth distribution of seismicity parameters estimated for the South American area, Earth Planet. Sc. Lett., $180,103-115,2000$

Updike, R. G., Egan, J. A., Moriwaki, Y., Idriss, I. M., and Moses, T. L.: A Model for earthquake-Induced Translatory Landslides in Quaternary Sediments, Geol. Soc. Am. Bull., 100, 783-792, 1988.

USGS-BGAT: U.S. Geological Survey-PetroBangla Cooperative Assessment of Undiscovered Natural Gas Resources of Bangladesh, US Geological Survey Bulletin 2208-A, US Geological Survey, available at: https://pubs.er.usgs.gov/publication/ b2208A, 2001.
Utsu, T.: A method for determining the value of $b$ in the formula log $N=a-b M$ showing the magnitude-frequency relation for the earthquakes, Geophys. Bull. Hokkaido Univ., 13, 99-103, 1965.

Utsu, T.: Statistical Features of Seismicity, International Handbook of Earthquake and Engineering Seismology, Part B, available at: www.eoas.ubc.ca/courses/eosc562/UTSU.pdf, 719-732, 2002.

Vaccari, F, Walling, M. Y., Mohanty, W. K., Nath, S. K., Verma, A. K., Sengupta, A., and Panza, G. F.: Site-Specific Modeling of SH and P-SV Waves for Microzonation Study of Kolkata Metropolitan City, India, Pure Appl. Geophy., 168, 479-493, 2011.

Vere-Jones, D.: Statistical methods for the description and display of earthquake catalogs, in: Statistics in the Environmental and Earth Sciences, edited by: Walden, A. T. and Guttorp, P., Arnold Publishers, London, 220-246, 1992.

Wald, D. J., Quitoriano, V., Heaton, T. H., and Kanamori, H.: Relationship between peak ground acceleration, peak ground velocity, and Modified Mercalli Intensity for earthquakes in California, Earthq. Spectra, 15, 557-564, 1999.

Wells, D. L. and Coppersmith, K. J.: New empirical relationships among magnitude, rupture length, rupture width, rupture area, and surface displacement, Bull. Seismol. Soc. Am., 84, 9741002, 1994.

Wong, I., Silva, W., Bott, J., Wright, D., Thomas, P., Gregor, N., Li, S., Mabey, M., Sojouner, A., and Wang, Y.: Earthquake scenario and probabilistic ground shaking maps for the Portland, Oregon, Metropolitanarea, Interpretative Map Series IMS-16, Oregon Department of Geology and Mineral Industries, Oregon, 2000.

Yamamuro, J. and Hade, P. V.: Experiments and modeling of silty sands susceptible to static Liquefaction, Mechanics of CohesiveFrictional Materials, Mech. Cohes.-Frict. Mater., 4, 545-564, 1999.

Yilmaz, I. and Bagci, A.: Soil liquefaction susceptibility and hazard mapping in the residential area of Kutahya (Turkey), Environ. Geol., 49, 708-719, 2006.

Youd, T. L. and Perkins, D. M.: Mapping liquefaction-induced ground failure potential, J. Geotech. Eng. Div., 104, 433-446, 1978.

Youd, T. L., Idriss, I. M., Andrus, R. D., Arango, I., Castro, G., Christian, J. T., Dobry, R., Finn, W. D. L., Harder Jr., L. F., Hynes, M. E., Ishihara, K., Koester, J. P., Liao, S. S. C., Marcuson-III, W. F., Martin, G. R., Mitchell, J. K., Moriwaki, Y., Power, M. S., Robertson, P. K., Seed, R. B., and Stokoe-II, K. H.: Liquefaction Resistance of Soils: Summary Report from the 1996 NCEER and 1998 NCEER/NSF Workshops on Evaluation of Liquefaction Resistance of Soils, J. Geotech. Geoenviron. Eng.-ASCE, 127, 817-833, 2001.

Youngs, R. R., Chiou, S. J., Silva, W. J., and Humphrey, J. R.: Strong ground motion relationships for subduction zone earthquakes, Seismol. Res. Lett., 68, 58-73, 1997. 